\title{
A multi-satellite study of accelerated ionospheric ion beams above the polar cap
}

\author{
R. Maggiolo ${ }^{1}$, J. A. Sauvaud ${ }^{1}$, D. Fontaine ${ }^{2}$, A. Teste ${ }^{2}$, E. Grigorenko ${ }^{3,4}$, A. Balogh ${ }^{5}$, A. Fazakerley ${ }^{6}$, G. Paschmann ${ }^{7}$, \\ D. Delcourt ${ }^{8}$, and H. Rème ${ }^{1}$ \\ ${ }^{1}$ CESR, 9 avenue du Colonel Roche, Toulouse 31028, France \\ ${ }^{2}$ CETP, 10 avenue de l'Europe, Vélizy 78140, France \\ ${ }^{3}$ Institute of Space Research (IKI), Moscow, Russia \\ ${ }^{4}$ SINP of Moscow State University, Russia \\ ${ }^{5}$ Space and Atmospheric Physics Group, The Blackett Laboratory, Imperial College, London, UK \\ ${ }^{6}$ MSSL, Holmbury St Mary, Dorking RH5 6NT, UK \\ ${ }^{7}$ MPI für extraterrestrische Physik, D-85748 Garching, Germany \\ ${ }^{8}$ CETP, 4 avenue de Neptune, Saint-Maur-des-Fossés 94107, France
}

Received: 16 September 2005 - Revised: 24 March 2006 - Accepted: 28 March 2006 - Published: 3 July 2006

\begin{abstract}
This paper presents a study of nearly field-aligned outflowing ion beams observed on the Cluster satellites over the polar cap. Data are taken at geocentric radial distances of the order of $5-9 R_{E}$. The distinction is made between ion beams originating from the polar cusp/cleft and beams accelerated almost along the magnetic field line passing by the spacecraft. Polar cusp beams are characterized by nearly field-aligned proton and oxygen ions with an energy ratio $\mathrm{E}_{\mathrm{O}+} / \mathrm{E}_{\mathrm{H}+}$, of the order of 3 to 4 , due to the ion energy repartition inside the source and to the latitudinal extension of the source. Rapid variations in the outflowing ion energy are linked with pulses/modifications of the convection electric field. Cluster data allow one to show that these perturbations of the convection velocity and the associated ion structures propagate at the convection velocity.

In contrast, polar cap local ion beams are characterized by field-aligned proton and oxygen ions with similar energies. These beams show the typical inverted V structures usually observed in the auroral zone and are associated with a quasi-static converging electric field indicative of a fieldaligned electric field. The field-aligned potential drop fits well the ion energy profile. The simultaneous observation of precipitating electrons and upflowing ions of similar energies at the Cluster orbit indicates that the spacecraft are crossing the mid-altitude part of the acceleration region. In the polar cap, the parallel electric field can thus extend to altitudes higher than 5 Earth radii. A detailed analysis of the distribution functions shows that the ions are heated during their
\end{abstract}

Correspondence to: R. Maggiolo

(maggiolo@cesr.fr) parallel acceleration and that energy is exchanged between $\mathrm{H}^{+}$and $\mathrm{O}^{+}$. Furthermore, intense electrostatic waves are observed simultaneously. These observations could be due to an ion-ion two-stream instability.

Keywords. Ionosphere (Particle acceleration) - Magnetospheric physics (Magnetosphere-ionosphere interactions; Polar cap ohenomena)

\section{Introduction}

The ionosphere has been shown to be an important source of magnetospheric plasma. It acts as a source of hydrogen and heavy ions (mainly $\mathrm{O}^{+}$) for the magnetosphere. The total mass supply has been estimated to be of the order of $1 \mathrm{~kg} \mathrm{~s}^{-1}$. For a recent review, see the papers of Yau and André (1997), André and Yau (1997) and Moore et al. (1999). The outflow of ions from the polar ionosphere takes a variety of forms: the polar wind, ions upwelling from the cleft ion fountain, polar cap outflows, upward ion conics and beams from the auroral zone. The strength and composition of these ionospheric plasma outflows vary with geomagnetic activity, season, solar cycle, local time, and altitude. Since the first observation of ionospheric energetic ions in the magnetosphere made by Shelley et al. (1972) in 1972, various acceleration mechanisms have been proposed. They include transverse ion acceleration, acceleration by parallel electric fields and various wave-particle instabilities. The high-latitude ionosphere thus appears as a region of foremost importance and interest, owing to its links with the distant magnetosphere

Published by Copernicus GmbH on behalf of the European Geosciences Union. 
and the tail, which are key regions for magnetosphere dynamics. At high latitude, energized precipitating ions are a common feature of magnetically active periods (e.g. Sauvaud et al., 1999; Korth at al., 2004).

The major source of upflowing ionospheric ions is the cleft ion fountain (Lockwood et al., 1985; Thelin et al., 1990), associated with the ionospheric projection of the polar cusp/cleft (Thelin et al., 1990). After their ejection from the dayside ionosphere, the ions are detected above the polar cap as they undergo the anti-sunward electric convection drift and escape along field lines. These cusp ion outflows have been studied using data from different satellites (see reviews by André and Yau 1997; Moore et al., 1999) but the properties of the outflow and of the source region are still under discussion.

Other polar cap ion outflows have been associated with optical structures caused by electron precipitation. These ions, originating from the polar cap ionosphere, are accelerated outward along the magnetic field line in the region corresponding to theta auroras or polar cap arcs (e.g. Shelley et al., 1982; Peterson and Shelley 1984). These arcs, generally parallel to the noon-midnight meridian, are indeed a common feature of the polar cap region during periods when the IMF points northward (e.g. Zhu et al., 1997). Although the polar cap arcs have been widely studied in the last decades, few studies focused on the detailed properties of associated ion escapes.

This paper presents observations of nearly field-aligned outflowing ion beams made on board the Cluster satellites over the polar cap. In this region, ions observed at any given point could originate from different source regions. After presenting briefly the instrumentation used in this study, we make a clear distinction between ion beams originating from the polar cusp and ion beams "locally accelerated", and characterize the particle and field properties associated with those different kinds of beams. While the cusp appears to be a continuous source of ionospheric plasma, polar cap outflows are triggered by precipitating electrons during periods of northward IMF.

\section{Instrumentation and observations}

The four identical Cluster satellites have been launched in 2000 on an elliptical orbit $\left(4.0 \times 19.6 R_{E}\right)$ with an inclination of $90^{\circ}$. A detailed description of the Cluster mission can be found in the paper of Escoubet et al. (2001).

We use data from the Cluster Ion Spectrometers (CIS) on board the Cluster spacecraft 1, 3 and 4 . The CIS instrument is described in detail in Rème et al. (2001). It consists of two different ion spectrometers, the Composition and Distribution Function analyser (CODIF), which can resolve the major magnetospheric ions, and the Hot Ion Analyzer (HIA), which has no mass resolution but higher angular and energy resolutions.
The Plasma Electron And Current Experiment (PEACE) (Johnstone et al., 1997) provides complementary electron data. In addition, we use data from the Cluster Fluxgate Magnetometers (FGM) (Balogh et al., 2001) and wave data collected by the STAFF instrument (Cornilleau-Wherlin et al., 1997). Electric fields are obtained via $\boldsymbol{E}=-\boldsymbol{V}_{d} \times \boldsymbol{B}$, using the FGM magnetic field data and the drift velocity measurement from the Electron Drift Instrument (EDI) (Paschmann et al., 2001).

The ACE and GEOTAIL data are used to monitor the solar wind conditions. The propagation time for the solar wind to attain the magnetosphere and then to communicate to the ionosphere has been computed using the method described by Jacobsen et al. (1995) with a varying position of the subsolar magnetopause (Sibeck et al., 1991).

A survey of Cluster CIS data has been performed to look for accelerated outflowing ion beams. The region of interest was the high-latitude magnetosphere, where the Cluster satellites' orbit is at radial distances between 5 and $9 R_{E}$. A series of events showing enhancement in the outflowing ions' energy have been selected. The energy of these $\mathrm{H}^{+}$and $\mathrm{O}^{+}$ion beams varies from a few tens of $\mathrm{eV}$ to a few $\mathrm{keV}$. They have been grouped into two categories, corresponding to different source regions and to different energization mechanisms. In this study we do not distinguish single particle velocities and ion bulk velocities, because, for a given ion species, the temperature is small compared to the bulk velocity. Thus, the distinction between those two velocities is hardly significant.

\subsection{Polar cusp ion beams}

Except during prolonged periods of northward IMF, a common feature above the polar cap is the observation of ionospheric ion beams originating from the cleft ion fountain. Using Cluster data during summer and autumn 2001, Bogdanova et al. (2004) have observed oxygen ion outflows from the polar cusp in $80 \%$ of all cusp crossing. First heated in the polar cusp region, these ions undergo an adiabatic convective flow, resulting in the observation of a cold, beam-like distribution above the polar cap. Previous detailed studies showed that $\mathrm{O}^{+}$ions outflow is caused by their resonant heating, by broad-band, extremely low-frequency electric field waves (BBELF turbulence), such as long wavelength Alfvén waves, ion acoustic waves and electrostatic ion cyclotron waves, or/and electromagnetic ion cyclotron waves (see a review by Moore et al., 1999). The contribution of the different waves to the acceleration process is still under discussion (e.g. Bouhram et al., 2002). The altitude location of the heating region was found to start at $\sim 2000 \mathrm{~km}$ (Moore et al., 1986). However, Dubouloz et al. $(1998,2001)$ and Bouhram et al. (2002) showed that the ion acceleration perpendicular to the magnetic field occurs at all altitudes extending up to $15000 \mathrm{~km}$. These ions, injected from a low altitude source on the dayside, will move upward along the magnetic field 

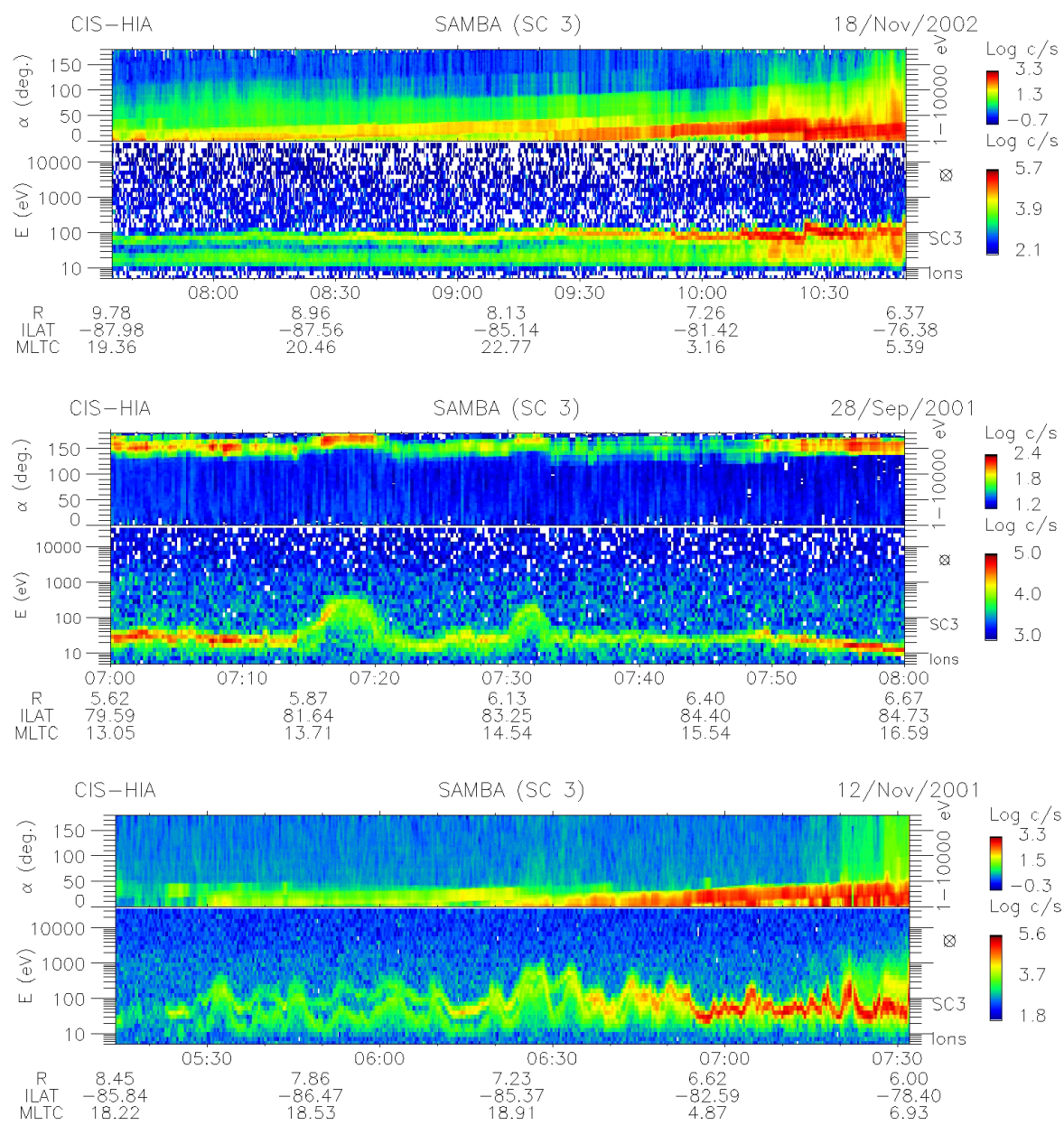

Fig. 1. HIA spectrograms for three polar cap crossings where the Cluster spacecraft detect ions originating from the cleft ion fountain. For each event, the top panel represents the pitch-angle distribution of the ions in the energy range of $10 \mathrm{eV}$ to $1000 \mathrm{eV}$ and the bottom panel is the ion energy-time spectrogram. Note that the pitch-angle is computed in the spacecraft frame.

line and end up at different locations, depending on the ratio between their velocity along the magnetic field line and the velocity at which the magnetic field line moves above the polar cap, i.e. the convection velocity.

Figure 1 shows three examples of energy spectrograms taken during polar cap crossings where Cluster spacecraft detect ions originating from the vicinity of the cusp region. For each event, the top panel represents the ion pitch-angle distribution and the bottom panel gives the energy-time spectrogram from HIA. Nearly field-aligned ions with energies up to $1 \mathrm{keV}$ are detected. The pitch-angle distribution is not very narrow but it must be taken into account that the CIS angular resolution is only $22.5^{\circ}$. Furthermore, this pitch-angle is measured in the satellite frame. It thus takes into account the convection velocity. At times, a regular latitude energy dispersion is observed (Fig. 1, first event) but these steadystate conditions are rarely achieved and many events show sporadic changes in the energy of outflowing ions along the Cluster trajectories. Note that when $\mathrm{H}^{+}$ion fluxes are above the detection threshold of the instrument, we clearly distinguish two well-separated energy bands corresponding to $\mathrm{O}^{+}$ and $\mathrm{H}^{+}$ions. Otherwise, we only detect one energy band corresponding to oxygen ions. The energies of protons and oxygen ions differ by a factor of about 4 , with oxygen ions being more energetic.

Neglecting the ion energy gain during their flight from the ionosphere to the high altitude polar cap and assuming that the ions originate from a narrow source, we could expect a ratio of the energies of oxygen and protons near 16. Indeed, ions with equal velocities will travel during the same time and be convected by the same amount during that time. This is clearly not the case, as exemplified by Fig. 1 .

A different approach emphasizes the ion energy gain during their travel from the ionosphere to the satellite. The ion relative energy gain, $\Delta \mathrm{E} / \mathrm{E}$, is a consequence of the number of equipotentials crossed under the effect of the magnetic drifts. It is proportional to the ion time of flight, and thus, for ions with identical initial energies, to the square root of their 


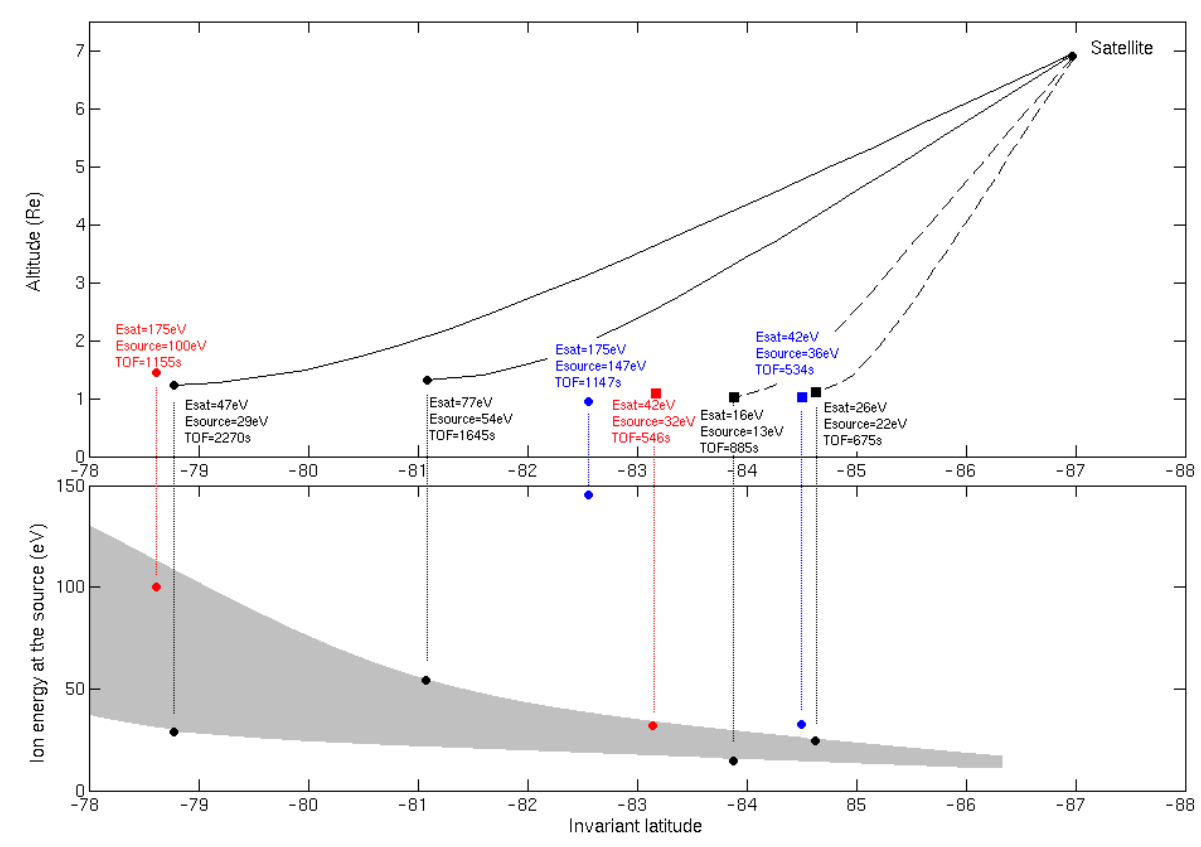

Fig. 2. Results of the backward particle simulations for the 12 November 2001 event. Top panel: Location of the mirror points in an altitude - invariant latitude diagram. The black solid lines represents $\mathrm{O}^{+}$ions trajectories for quiet conditions. The black dotted line represents $\mathrm{H}^{+}$ ions trajectories for quiet conditions. The points mark the mirror points of $\mathrm{O}^{+}$(black for quiet conditions, blue for particles experiencing a short duration burst of convection and in red for particles experiencing a convection twice the regular quiet convection during their entire path from the source to the satellite). The squares mark the mirror points of $\mathrm{H}^{+}$with the same color code as for $\mathrm{O}^{+}$ions. The energy of the particles at the spacecraft and inside the source, and their computed times of flight are also indicated. Bottom panel: Corresponding particle energies at the source versus latitude. The grey region schematically represents the ion energy distribution at the source. The shape of this energy-latitude structure is defined by the backward computations and by using simple arguments about the connection between the source and the satellite: if at lower latitudes than the computed latitudes there were particles with lower energies than that computed, then they would be measured on board the spacecraft, which is not the case.

masses (e.g. Sauvaud and Delcourt, 1987). Assuming that the $\mathrm{O}^{+}$and $\mathrm{H}^{+}$ions have the same small initial energy and that the energy gains are large, the ratio of their final energies should be close to the square root of their mass ratio.

To check the importance of the convection versus energy gain scenario, we performed backward particle trajectory calculations in 3-D models of the magnetic and electric field, as described by Sauvaud and Delcourt (1987) and Delcourt et al. (1988). Test particles were traced backward in time, using the Tsyganenko (1989) model for the magnetic field, together with the Volland (1978) model for the electrostatic potential distribution in the ionosphere. The convection electric field encountered by the ions during their transport is obtained by assuming that the magnetic field lines are equipotentials. Particles are followed until they reach their mirror point, which we assume to be the source region.

Figure 2 gives the results obtained for ions detected during the 12 November 2001 event on spacecraft 3 at 5:35:30 UT, i.e. between two sporadic enhancements of the ion energy. The computations have been made for ion energies covering the energy range of the ions detected at the Cluster altitude and for ion pitch-angles computed in the plasma frame. It is immediately apparent that $\mathrm{O}^{+}$and $\mathrm{H}^{+}$ions, with the measured final energies (47 to $77 \mathrm{eV}$ for $\mathrm{O}^{+}$and 16 to $26 \mathrm{eV}$ for $\mathrm{H}^{+}$), do not come from the same invariant latitude. The source region extends over a broad latitudinal range from about $\sim 79^{\circ}$ for oxygen ions to $\sim 85^{\circ}$ for protons. Similar results are obtained for the 18 November 2002 event.

This is in agreement with the results obtained with Interball AP (Dubouloz et al., 2001) and with low altitude measurement from Polar by Valek et al., 2002, who identified ionospheric outflow in the vicinity of the cusp, in a region extending about $5^{\circ}$ poleward of the cusp equatorward boundary and also report that the velocity and temperature of those outflowing ions decrease poleward of the cusp equatorward boundary. It must be stressed that Interball data during the events presented by Dubouloz et al. (2001) also display the same kind of energy-latitude distribution for ions close to the source.

Similarly, we find that the source provides the lowest energy particles (protons) from the highest latitudes. Figure 2 shows that $\mathrm{O}^{+}$and $\mathrm{H}^{+}$do not have the same energy at the source, oxygen ions being more energetic than protons (29 to $54 \mathrm{eV}$ for $\mathrm{O}^{+}$and 13 to $22 \mathrm{eV}$ for $\mathrm{H}^{+}$). Furthermore, the 


\section{$12 / \operatorname{Nov} / 2001$}

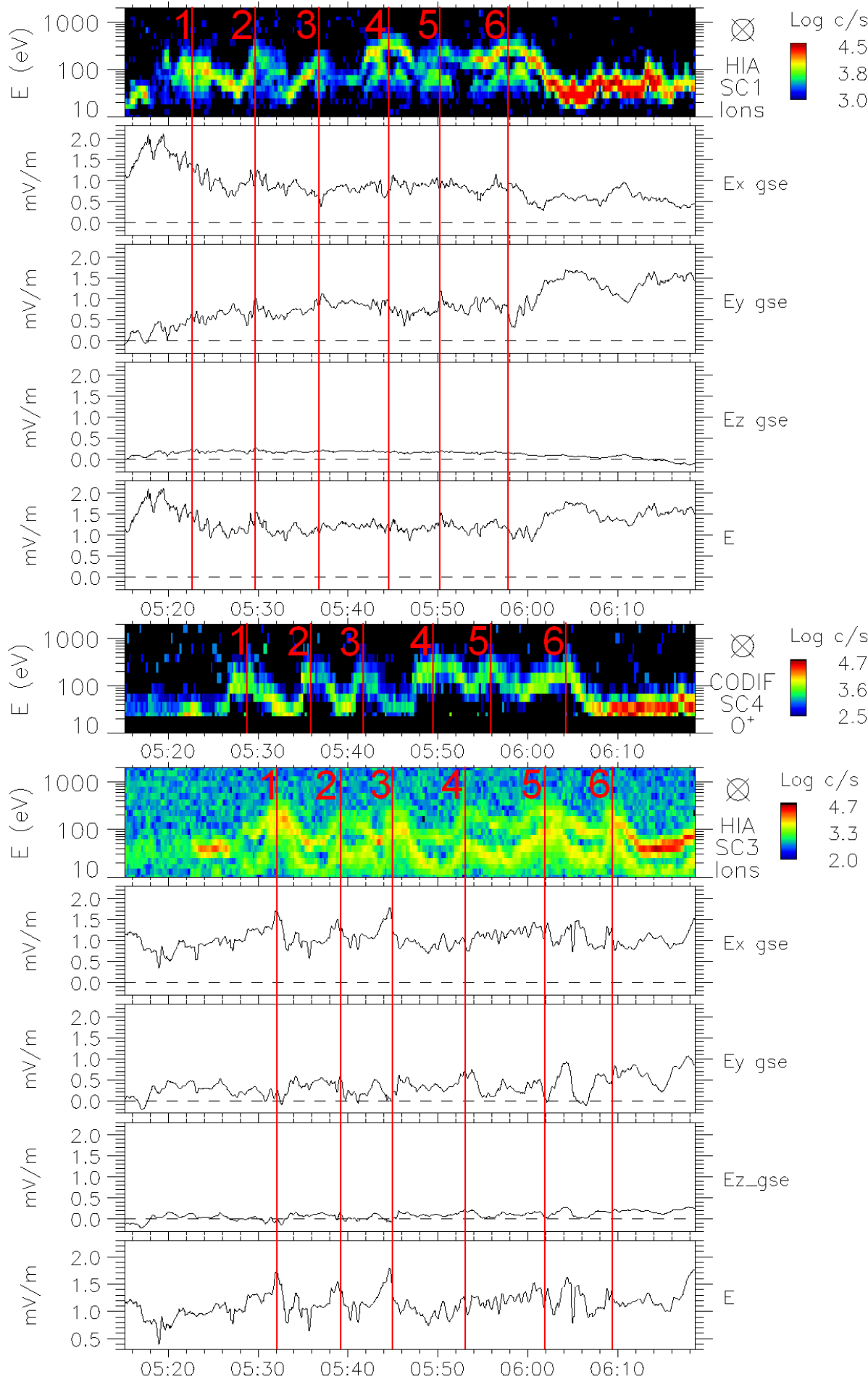

Fig. 3. 12 November 2001. From top to bottom: Energy-time spectrogram from HIA for all ions, spacecraft 1 . GSE components and modulus of the convection electric field as given by EDI, spacecraft 1 . Energy-time spectrogram from CODIF for $\mathrm{O}^{+}$ions, spacecraft 4 . Energy-time spectrogram from HIA for all ions, spacecraft 3. GSE components and modulus of the convection electric field as given by EDI, spacecraft 3 . 

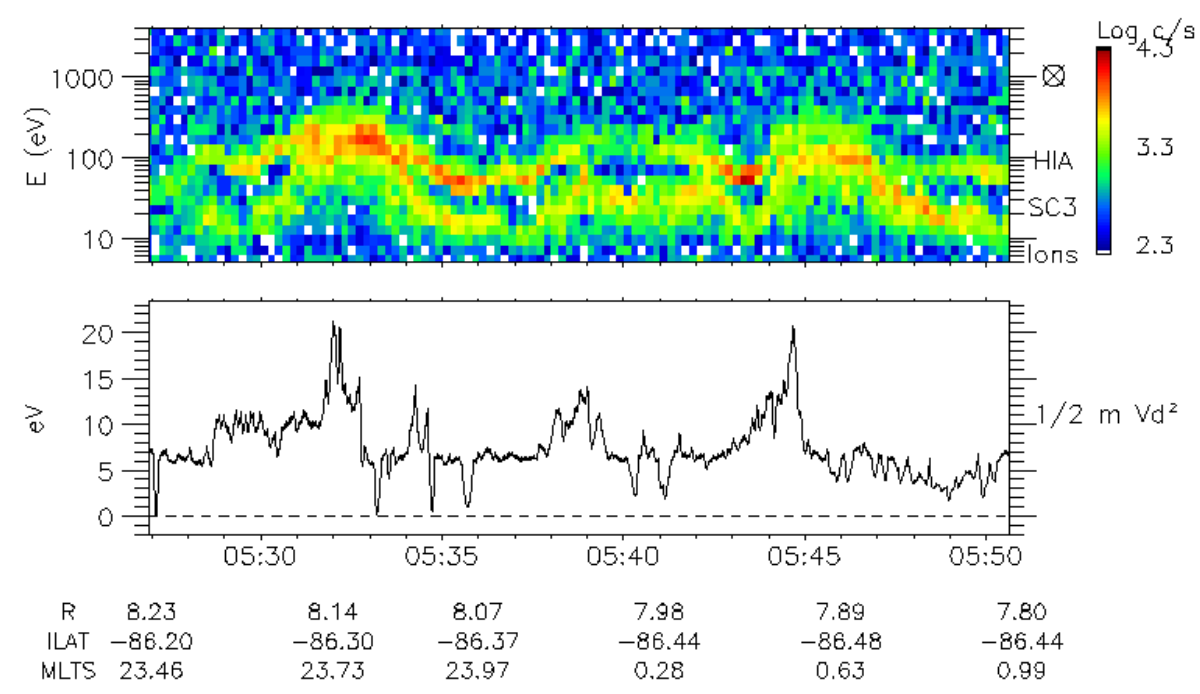

Fig. 4. 12 November 2001. Top panel: Energy-time spectrogram from HIA for all ions. Bottom panel: Energy variation for $\mathrm{O}^{+}$ions corresponding to the convection velocity given by EDI.

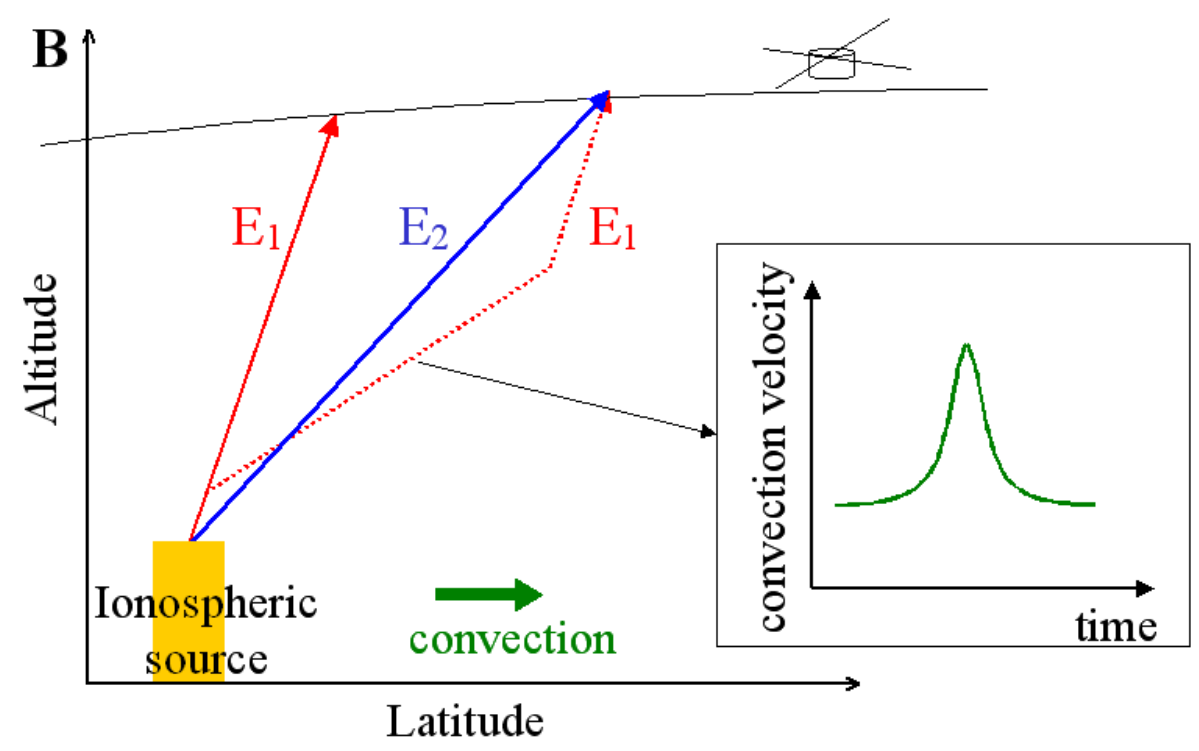

Fig. 5. Schematic description of the effect of a pulse of the convection electric field on the particle path. $E_{1}$ and $E_{2}$ refer to the particle energy: $E_{1}>E_{2}$. Solid lines: regular velocity filter effect. Dashed line: effect of a pulse of convection velocity.

ion energy gain during their transport (18 to $23 \mathrm{eV}$ for $\mathrm{O}^{+}$ and 3 to $4 \mathrm{eV}$ for $\mathrm{H}^{+}$) is low compared to the ion initial energy. The computations thus indicate that the energy gain scenario is not at the root of the measured energy ratio between oxygen ions and protons. This ratio is rather related to the characteristics of the source region, i.e. to its spatial extent and to the energy repartition of the heated ionospheric ions inside the source. The grey region in the bottom panel of Fig. 2 schematically represents the ion energy repartition at the source which is suitable to explain the Cluster observations. This energy variation is in agreement with measurements of upflowing ionospheric ions done inside the cusp at lower altitudes (Valek et al., 2002).

As shown previously, many events are associated with sudden variations of the ion energy. For these types of events, which have been observed on board the Cluster spacecraft (Bouhram et al., 2004; Nilsson et al., 2004), either isolated or multiple bumps in the ion energy are registered. As clearly 
$18 / \mathrm{Nav} / 2002$
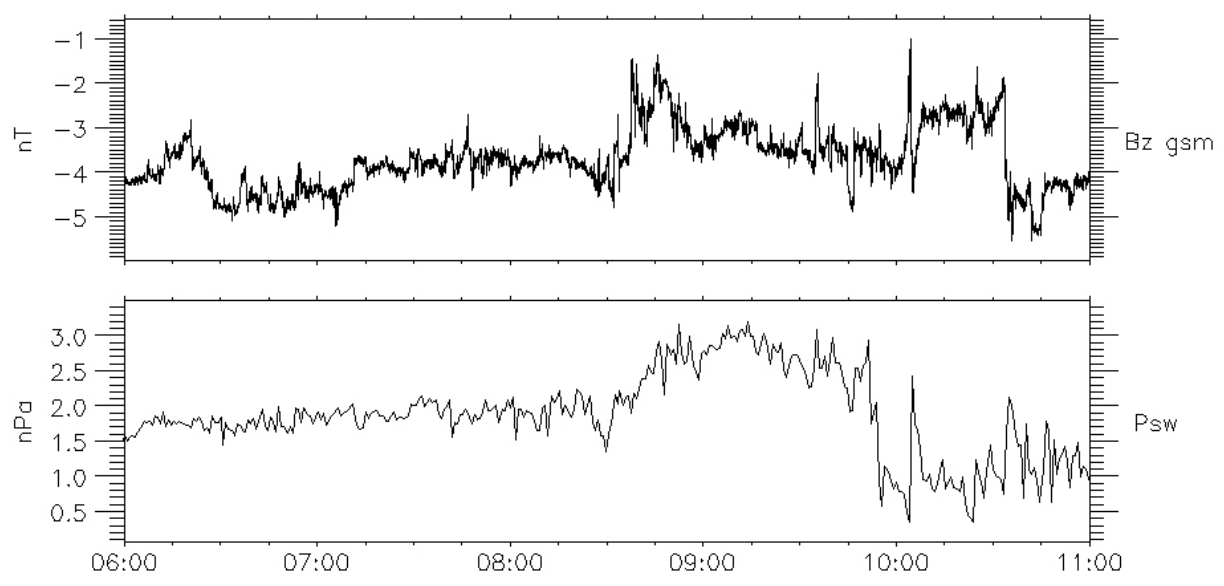

$28 / \operatorname{Sep} / 2001$
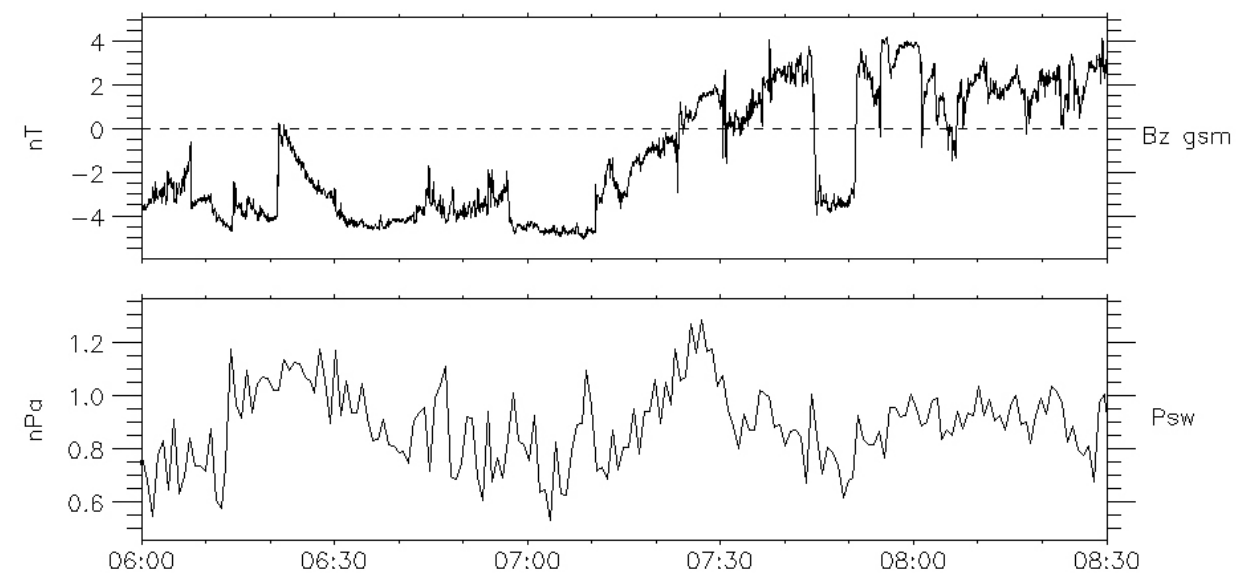

$12 / \mathrm{Nav} / 2001$
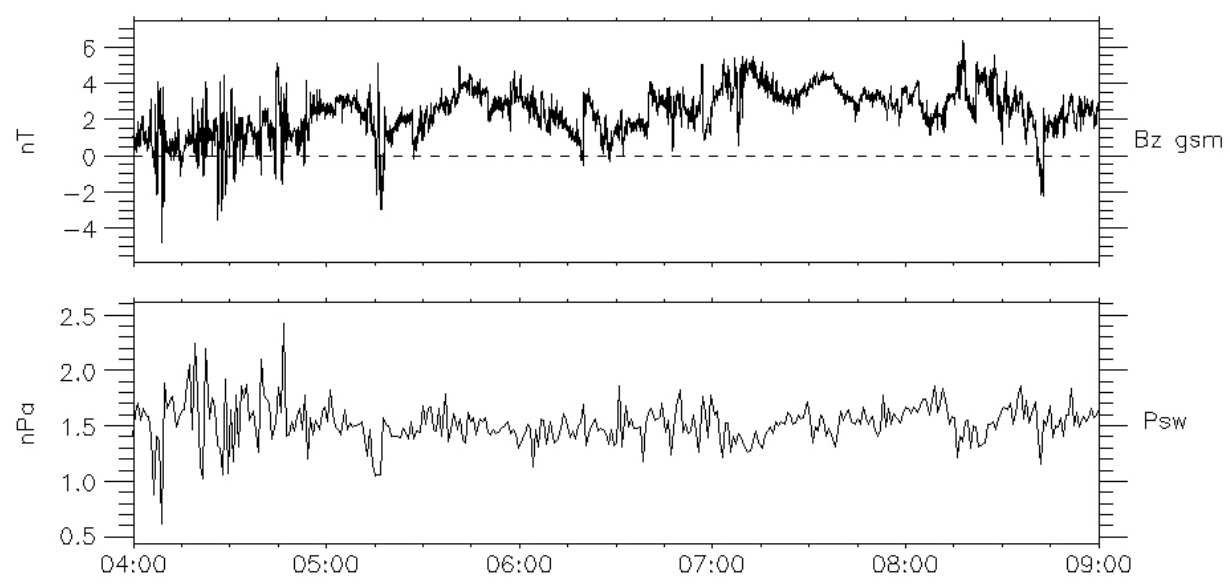

Fig. 6. IMF $B_{z}$ component and solar wind pressure as provided by GEOTAIL for the polar cap crossings displayed in Fig. 1. 


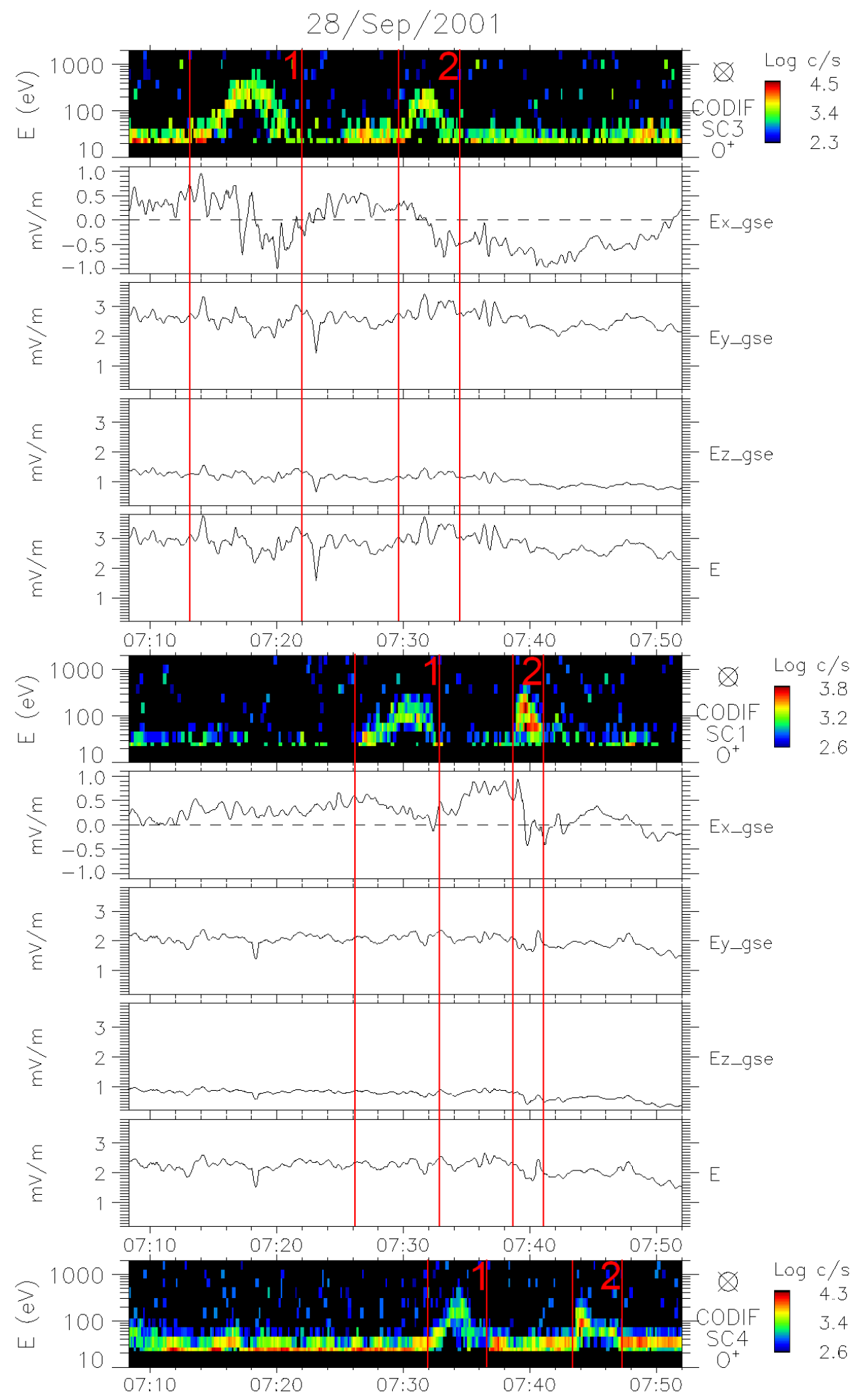

Fig. 7. 28 September 2001. From top to bottom: Energy-time spectrogram from CODIF for $\mathrm{O}^{+}$ions, spacecraft 3 . GSE components of the convection electric field as given by EDI, spacecraft 3 . Energy-time spectrogram from CODIF for $\mathrm{O}^{+}$ions, spacecraft 1 . GSE components of the convection electric field as given by EDI, spacecraft 1 . Energy-time spectrogram from CODIF for $\mathrm{O}^{+}$ions, spacecraft 4 . The scale used to plot the $\mathrm{x}$ component of the electric field differs from the others, in order to better show its variation associated with the ion structures. 


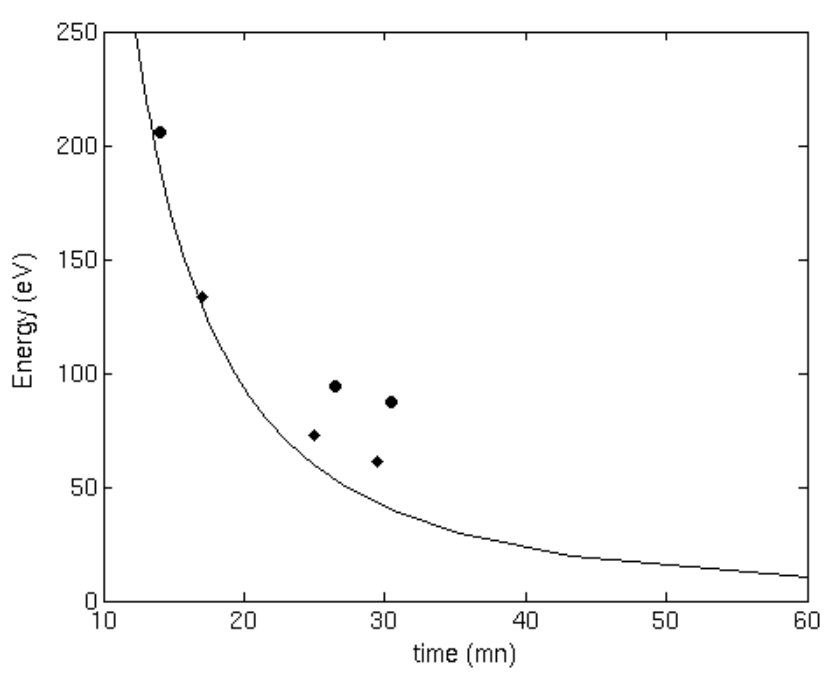

Fig. 8. Time evolution of the energy of the ion structures as deduced from 3 satellite measurements for the 28 September 2001 event. Points correspond to the structure number 1 and the diamondshaped symbols to the structure number 2 (the number refers to the structures' label as given in Fig. 7). The line represents the time of flight of $\mathrm{O}^{+}$ions, deduced from a dipolar model.

evidenced by the last two events of Fig. 1, both inside and outside these energy enhancements, ions show the narrow energy distribution characterizing a cold beam. The ion temperature is of the order of $\sim 10 \mathrm{eV}$. Furthermore, the ion energy before and after the events is nearly the same.

Using CIS ion measurements and the EDI electric field deduced from the measured drift velocity, we were able to relate the increases in the ion energy to local changes in the polar cap electric field. Figure 3 displays such Cluster measurement during a polar cap crossing over the Southern Hemisphere taken on 12 November 2001. During this crossing, the spacecraft were located at invariant latitudes ranging from $-87^{\circ}$ to $-78^{\circ}$ and at radial distances between 8.5 and $6.0 R_{E}$. The spacecraft are approximately travelling in the dusk to dawn direction. They detect several successive ion energy variations, as evidenced in Fig. 3, which displays the corresponding HIA ion energy-time spectrograms and the variations in the three GSE components of convection electric field (for spacecraft 4 CODIF data for $\mathrm{O}^{+}$ions are plotted). During this time interval, spacecraft 1, 3 and 4 detect 6 energy structures similar in terms of energy variation and duration at different locations. Some of them are clearly associated with short duration increases of the convection electric field; see, for example, the sudden increase in the convection electric field for spacecraft 3 during the first 3 structures, from about $1 \mathrm{mV} / \mathrm{m}$ to $1.8 \mathrm{mV} / \mathrm{m}$. However, the following enhancements in the outflowing ion energy are not clearly related to fluctuations of the local electric field. Thus, these local variations of the electric field cannot directly explain

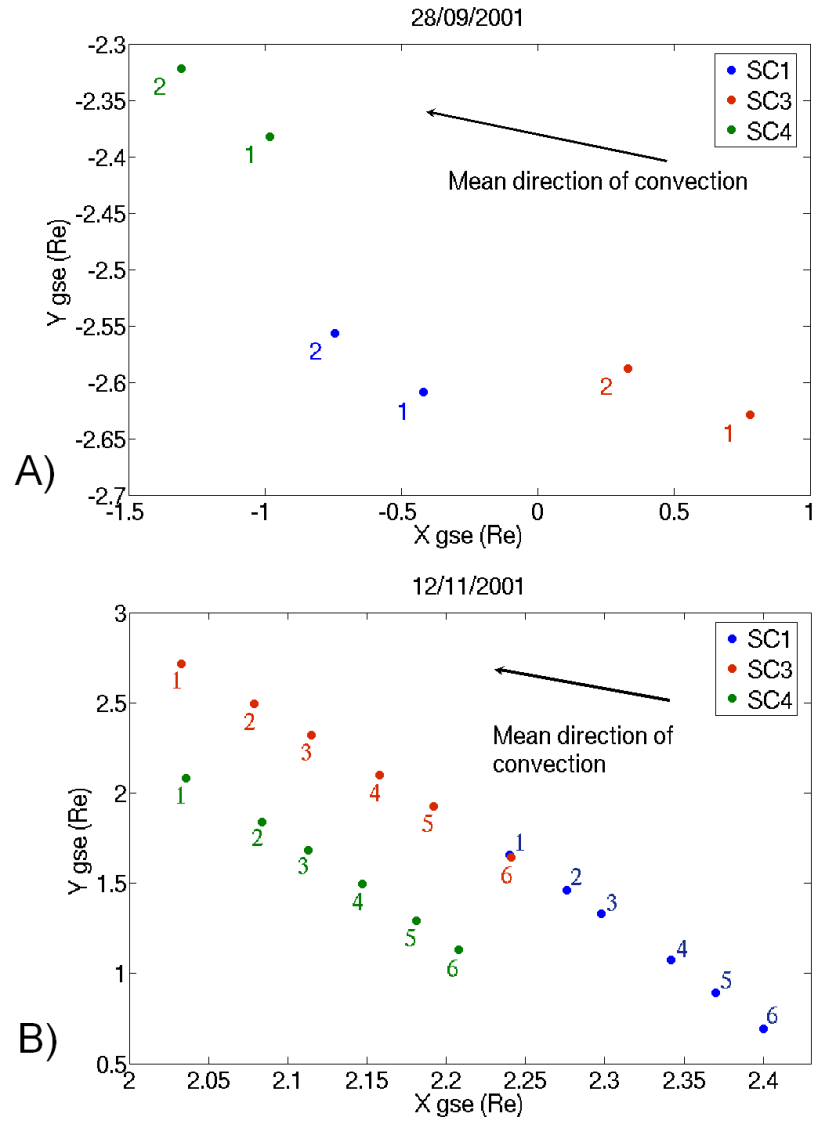

Fig. 9. Cluster spacecraft location at their encounter with the ion energetic structures. The number refers to the structures' label as given in Figs. 3 and 7. It must be taken into account that the ratio of the $\mathrm{X}$ and $\mathrm{Y}$ axes differs from one panel to another.

the observed changes in the outflowing ions. Furthermore, as displayed in Fig. 4, even when the local electric field is enhanced, the expected local variation of the ion perpendicular velocity is too low to explain the observed ion energy variation. This indicates that the fluctuations in the outflowing ion energy are preferentially due to a modification of the drift path, which brings to the satellite ions travelling at higher altitudes, i.e. having a higher parallel velocity (e.g. Delcourt et al., 1996). This is illustrated in Fig. 5, which very schematically illustrates the effect of a convection pulse on the ion trajectories above the polar cap.

Such changes in the convection pattern are expected to be linked to changes in the orientation of the IMF and/or to solar wind pressure pulses. Figure 6 displays the IMF conditions as deduced from GEOTAIL measurements during the 3 events presented Fig. 1. These events are associated with various IMF conditions but we verified from EDI measurements that the overall convection was anti-sunward inside the polar cap. Note that for 18 November $2002, B_{z}$ is always negative. In contrast, during the 28 September 2001 event 
Table 1. The structure's velocity computed from the Cluster fleet.

\begin{tabular}{|c|c|c|c|}
\hline Date & Structure & $\mathrm{S} / \mathrm{C}$ & Velocity $(\mathrm{km} / \mathrm{s})$ \\
\hline \multirow[t]{7}{*}{12 Nov 2001} & 1 & $1-4$ & 7.5 \\
\hline & 2 & $1-4$ & 5.3 \\
\hline & 3 & $1-4$ & 4.9 \\
\hline & 4 & $1-4$ & 8.8 \\
\hline & 5 & $1-4$ & 6.5 \\
\hline & 6 & $1-4$ & 9.3 \\
\hline & \multicolumn{2}{|c|}{ Mean convection velocity } & 7.5 \\
\hline Date & Structure & $\mathrm{S} / \mathrm{C}$ & Velocity $(\mathrm{km} / \mathrm{s})$ \\
\hline \multirow[t]{7}{*}{28 Sep 2001} & \multirow[t]{3}{*}{1} & $1-3$ & 10.0 \\
\hline & & $1-4$ & 10.6 \\
\hline & & $3-4$ & 12.9 \\
\hline & \multirow[t]{3}{*}{2} & $1-3$ & 13.0 \\
\hline & & $1-4$ & 12.8 \\
\hline & & $3-4$ & 12.9 \\
\hline & \multicolumn{2}{|c|}{ Mean convection velocity } & 11 \\
\hline
\end{tabular}

there are some northward incursions of the IMF and for the 12 November 2001 event the IMF is southward only briefly. The analysis of ten cases shows the tendency that the more the IMF $B_{z}$ component fluctuates, the more the ion energy varies, although no one-to-one correlation between the IMF fluctuations and the acceleration structures can be found. In contrast, no clear association between the variation of the solar wind pressure and the variation of the ion energy detected by the Cluster spacecraft has been found. A quite similar result was reported by Bouhram et al. (2004), who studied similar events and found that $70 \%$ of them were associated with several turnings of the IMF $B_{z}$ component and steady solar wind bulk parameters. Note that the behaviour of the steady-state ionospheric convection is generally well understood but that its response to the changing IMF is still under discussion. The main debate concerns the time scale of these changes; a nearly simultaneous response to IMF variations or a response propagating at low velocity from the dayside in the antisunward direction (e.g. Ridley et al., 1999; Lockwood and Cowley, 1999).

During the pass of 28 September 2001, spacecraft 1, 3 and 4 detected two successive enhancements in the outflowing ion energy at different locations (Fig. 7). The satellites were in a string-of-pearls configuration, nearly travelling from noon to midnight at an invariant latitude between $79^{\circ}$ and $85^{\circ}$ and at a radial distance between 5.5 and $6.5 R_{E}$. Here $\mathrm{C} 4$ is the leading spacecraft, and $\mathrm{C} 1$ and $\mathrm{C} 3$ are lagged with respect to $\mathrm{C} 4$, by about $11 \mathrm{~min}$ and $33 \mathrm{~min}$, respectively. Figure 7 depicts the corresponding CODIF $\mathrm{O}^{+}$energy-time spectrograms and the local electric field components, except for spacecraft 4 for which no electric field data from EDI is available. The bumps in the ion energy are short in duration, less than $5 \mathrm{~min}$, and the ion energy varies from a few tens of $\mathrm{eV}$ to a few hundreds of $\mathrm{eV}$. As expected for a structure propagating from the dayside towards midnight, the energy increase is first detected on board satellite 3 and later on board satellites 1 and 4 . The electric field data taken on board spacecraft 1 and spacecraft 3 indicate that the energy structures in the ion spectrogram are associated with local modifications of the $\mathrm{X}$ component of the convection electric field, with almost no associated modification of the total electric field. Indeed, each of the two structures is associated with a decrease of the order of $1 \mathrm{mV} / \mathrm{m}$ of the $\mathrm{X}$ component of the convection electric field which passes from positive to negative values. However, the main component of the electric field, $\boldsymbol{E}_{y}$, is almost unchanged. This modification of the local electric field, which corresponds to a diverging electrical structure, may be due to a change in the local electrodynamics linked to the ion cloud propagating from the dayside. For the cusp events presented here, electron data reveal subtle changes that are beyond the scope of this paper.

The high separation distance between the satellites during this event allowed us to study the evolution of the ion structures. The later the spacecraft crosses the structures, the less energetic they are. This observation is valid for both structures shown in Fig. 7. Figure 8 displays the time evolution of the ion mean energy as deduced from 3 Cluster spacecraft. We compare it to the time needed for $\mathrm{O}^{+}$ions of different energies to travel from an altitude of $1 R_{E}$ to an altitude of $6 R_{E}$. Those ions were chosen in order to have a pitch-angle of $90^{\circ}$ at the altitude of $1 R_{E}$. Time evolutions for both structures are in good agreement and we conclude that the decrease in the energy of the structures is probably due to the fact that during its motion above the polar cap, the flux tube is emptied of its particles. The first particles able to reach the Cluster altitude are the more energetic ones. As time passes, 
Cluster detects lower energy particles whose time of flight from the source to the spacecraft is higher.

The ion measurements simultaneously performed on board satellites 1, 3 and 4, presented in Figs. 3 and 7, allow to compute the velocity of the ion energy structure along the satellites' separation line, assuming that the spacecraft detect the same structures. During the 28 September 2001 event, the spacecraft motion and separation are approximately along the convection path (Fig. 9A). This made it possible to compare the velocity of the structures with the convection velocity given by EDI. For the 12 November 2001 event the spacecraft orbits were less convenient. However, spacecraft 1 and 4 are approximately located at the same $z_{-}$gse. Thus we computed the structures' velocities in the $x_{-}$gse plane and compared them with the convection velocity deduced from Cluster 1 (see spacecraft position in Fig. 9B). Here the B field is roughly perpendicular to the xy_gse plane and thus the convection velocity is approximately contained in this plane. The results are summarized in Table 1 .

The velocity of the ion energy structures and the convection velocity are very similar, indicating that the energy enhancements propagate at nearly the convection speed. For the 28 September 2001 event we can also conclude that the associated modification of the local electric field is embedded in the overall convection pattern and propagates at the convection velocity. Concerning the 12 November 2001 event, we do not have a good enough correlation between the electric field measurements performed on board different spacecraft to reach a firm conclusion about the velocity of the electric field structures.

These observations indicate that the variations in the ion energy are consistent with a modification of the particle path from the source to the spacecraft, due to a burst in the convection electric field possibly triggered by changes of the IMF.

For the events presented here the energy structures last a few minutes ( less than $5 \mathrm{~min}$ ), which corresponds to $\sim 2000 \mathrm{~km}$, and the energy variation is very sharp, about a factor 4 within 1 or $2 \mathrm{~min}$. To produce such thin structures we can consider different types of modifications of the convection pattern:

i) A large-scale pulse of convection. Since the duration of the energy structure is shorter than the estimated ion travel time from the source to the satellite $(\sim 15 \mathrm{~min}$ for a $200 \mathrm{eV} \mathrm{O}^{+}$), the associated electric field burst must also of short in duration. As shown in Fig. 3, many energy bursts are detected successively during a $15 \mathrm{~min}$ time interval. Both the low energy particles outside the bursts and the more energetic particles inside the bursts should have experienced the large-scale E field changes. In this case the average electric field experienced by the ions inside and outside the burst would be quite similar and could not account for their difference in energy.

ii) A localised pulse of convection in a fixed and restricted region between the source and the spacecraft. Here as well, the enhancement of the electric field cannot be long-lasting, otherwise, it will produce a long-lasting ion structure. The effect of such a burst on the ion trajectories is shown in Fig. 2 (blue points and squares). Because the bursts are short in duration, compared to the particle time of flight, their effect on particle trajectories are weak. They would lead to a source region located at high latitude corresponding to ions with high energies $\left(147 \mathrm{eV}\right.$ for $\mathrm{O}^{+}$and $36 \mathrm{eV}$ for $\left.\mathrm{H}^{+}\right)$. This is in contradiction with the energy-latitude repartition of the ions inside the source as deduced from the trajectories of the ions detected just before and after the peaks.

iii) A localized pulse of convection in a region moving at a velocity comparable to that of the ions. In this case, the ions see a long-lasting electric field enhancement. The corresponding trajectory is plotted in red in Fig. 2. In this case, the particle's energy at the source is significantly higher than the energy of particles detected just near the peaks and their mirror point are located at lower latitudes which is in agreement with the properties of the source region deduced from the study of particle characteristics outside the bursty events.

Thus, of the three hypothesis discussed above, the third is the most likely to explain the observations. Such convection changes propagating from the cusp in the antisunward direction have been discussed by Cowley (1992) in the framework of magnetic reconnection at the dayside magnetopause. According to Cowley's model, the flow modification is first initiated in the noon sector and then spreads toward the dawn and dusk sectors with an expansion velocity from noon of a few $\mathrm{km} \mathrm{s}^{-1}$, a velocity which is comparable with the convection velocity. As proposed by Cowley (1992), this region of enhanced flow is not necessarily extending perpendicularly to the direction of the background convection and attenuates as it propagates. This can explain why during the 12 November 2001 event the convection pulses are detected by spacecraft 3 only for the first three structures and why spacecraft 1 doesn't detect them. Experimentally, a very detailed study of the correlation between southward turnings of the IMF and polar cap convection changes was reported by Jayachandran and MacDougall (2000) using ground measurements from a chain of Canadian Advanced Digital Ionosondes (CADI). CADI gives the convection velocity from Doppler measurements. Jayachandran and MacDougall distinguished between two kinds of responses: i) an initial response propagating at the Alfvén velocity, i.e. detected nearly simultaneously over the entire polar cap, and ii) if the change in IMF is rapid enough, a step in the convection propagating antisunward above the polar cap at the convection velocity.

Finally, it must be stressed that the ion beams shown in Fig. 1 are apparently flowing closer to the magnetic field during the bursts of convection. However, in the plasma frame, ions detected inside and between the energy structures are 

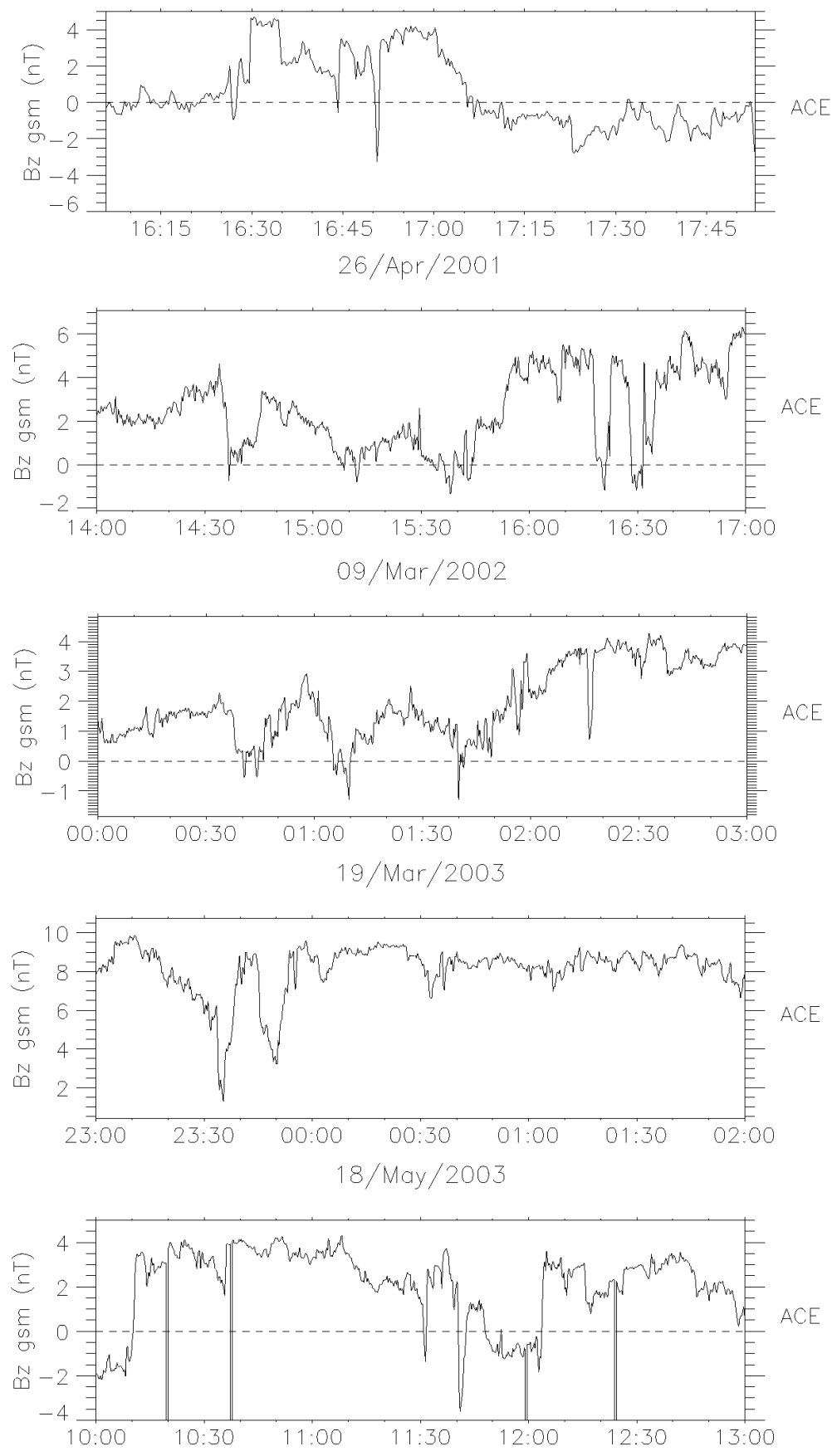

Fig. 10. The solar wind IMF $B_{z}$ component from the ACE spacecraft during typical polar cap crossings when Cluster encountered ionospheric ion beams.

quasi-field-aligned, due to the mirror force, and their apparent pitch-angle differs in the satellite frame due to the effect of convection velocity. Indeed, for "high energy" ions, the convection velocity is small compared to the parallel velocity and thus ions appears as field-aligned in the spacecraft frame.
For low energy ions, the convection velocity $(\sim 10 \mathrm{~km} / \mathrm{s})$ is not negligible compared to the parallel velocity. Thus, when detected in the spacecraft frame such ions will appear as less field-aligned. For example, the pitch-angle of a $50 \mathrm{eV} \mathrm{O}^{+}$ ion aligned to the magnetic field in the plasma frame will be 


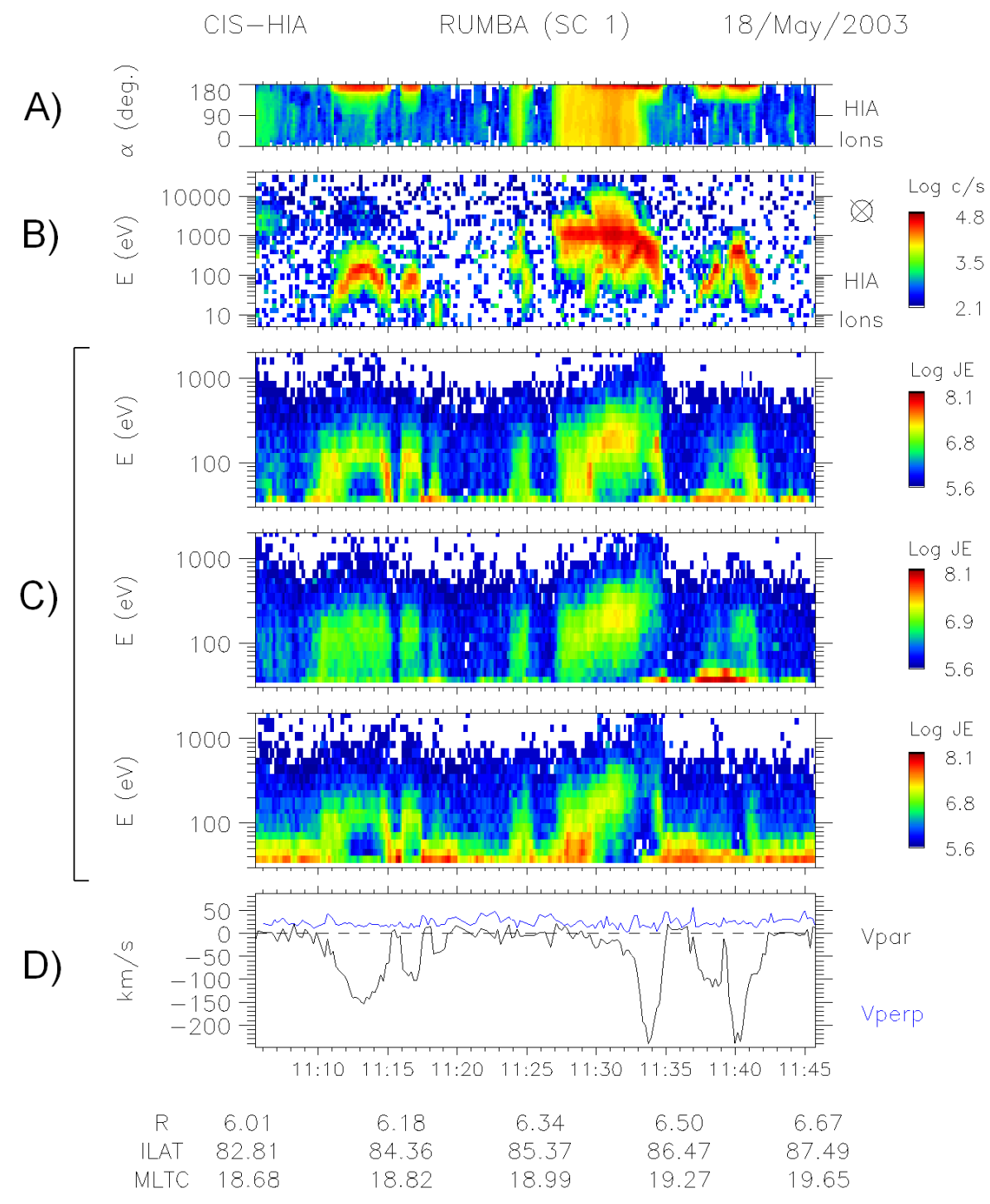

Fig. 11. 18 May 2003. (A) Pitch-angle distribution from HIA for all ions. (B) Energy-time spectrogram from HIA for all ions. (C) Energytime spectrogram from PEACE. From top to bottom: downgoing electrons, electrons perpendicular to the magnetic field and upgoing electrons. (D) Ion perpendicular velocity (blue) and parallel velocity (black) computed from HIA.

$\sim 24^{\circ}$ in the satellite frame for an $\boldsymbol{E} \times \boldsymbol{B}$ velocity of $10 \mathrm{~km} / \mathrm{s}$. It is in good agreement with the pitch-angle measured for similar conditions, for example, during the 12 November 2001 event at 06:15 UT (see Fig. 1).

\subsection{Polar cap local beams}

Mainly during low geomagnetic activity periods and northward IMF, the Cluster satellites detect ion beams in the energy range of a few $\mathrm{eV}$ to a few $\mathrm{keV}$ leaving the polar ionosphere. These beams are characterized by strongly fieldaligned $\mathrm{H}^{+}$and $\mathrm{O}^{+}$ions with similar energies showing the typical inverted $\mathrm{V}$ structure usually observed in the auroral zone. Examples of IMF $B_{z}$ associated with these polar cap ion beams are given in Fig. 10. While during some events the IMF $B_{z}$ is alternatively positive and negative, these events are preferentially observed during periods where the IMF is mostly northward oriented. Such northward IMF conditions are generally associated with polar cap arcs (Zhu et al., 1997).

Typical measurements of such ion beams taken on 18 May 2003 between approximately 11:05 UT and 11:45 UT are given in Fig. 11. During this polar cap crossing, the spacecraft encounters multiple outflowing ion beams as evidenced by the upper panel showing the ion pitch-angle distribution (in the Northern Hemisphere a $180^{\circ}$ pitch angle corresponds to upward flow). Across each extended beam region the ion energy varies by more than one order of magnitude, whereas 


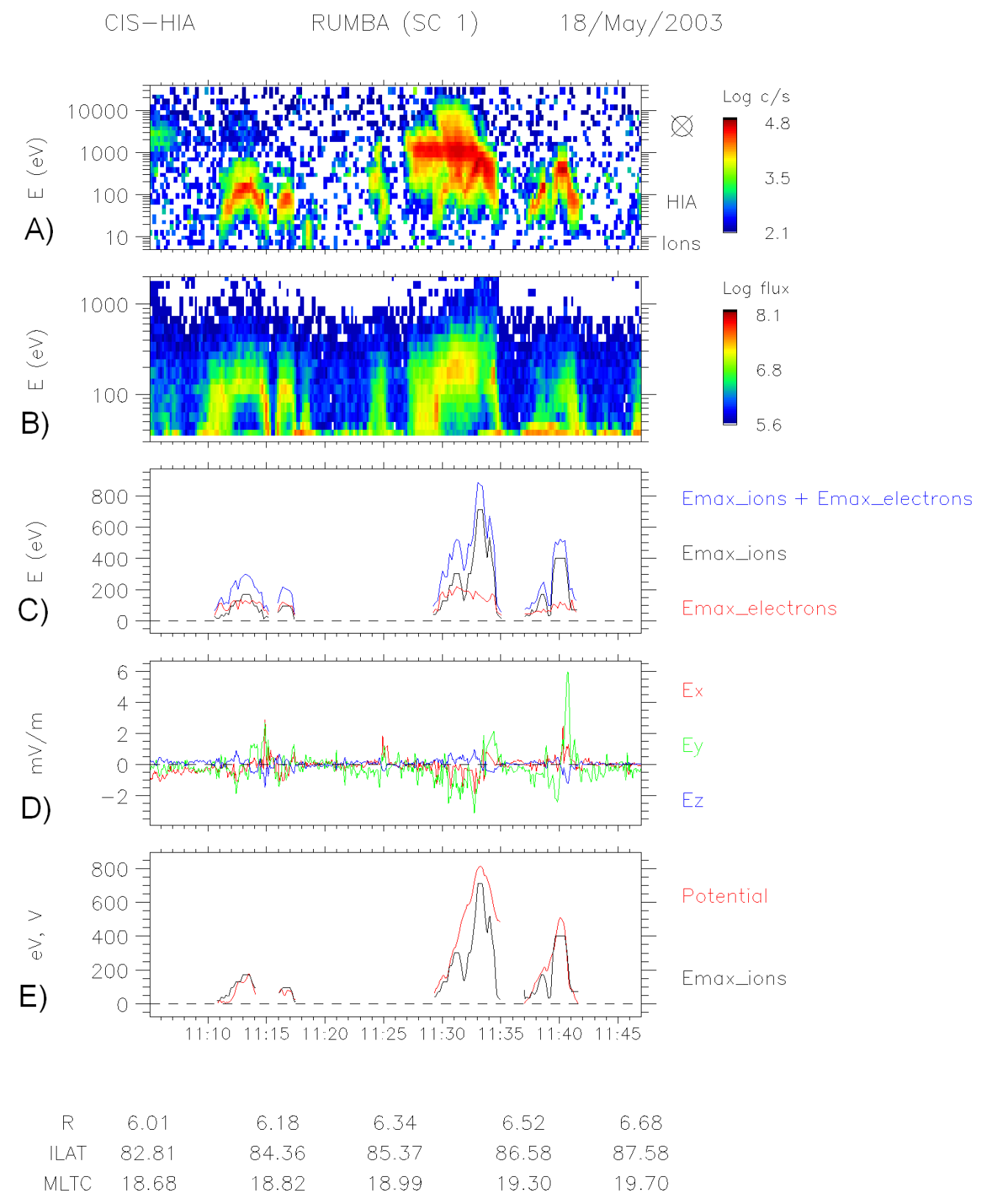

Fig. 12. 18 May 2003. (A) Energy-time spectrogram from HIA for all ions. (B) Energy-time spectrogram from PEACE for downgoing electrons. (C) Comparison of the energy of ions (upflowing, back) and electrons (downgoing, red) at maximum of fluxes. The total energy (upflowing ion energy + downgoing electron energy) is plotted in blue. (D) GSE components of the perpendicular electric field as given by EDI, spacecraft 1. (E) Electric potential along the spacecraft trajectory (red curve) computed from EDI data and energy of the maximum of ion fluxes (black curve).

between them almost no ions are detected (panel B). Ions reach energy of some hundred $\mathrm{eVs}$, corresponding to velocity antiparallel to $\boldsymbol{B}$ of about $150 \mathrm{~km} / \mathrm{s}$ for hydrogen, whereas the perpendicular velocity doesn't exhibit any related variation (panel D). These observations indicate that the ions we observe inside the energy structures have been accelerated upward in the direction parallel to the magnetic field.
Note that the inverted V structure around 11:30:00 UT is associated with another population in the energy range from $1 \mathrm{keV}$ to $10 \mathrm{keV}$, consisting of a hot and isotropic hydrogen plasma. Because of the composition, pitch-angle and energy spectral characteristics of this latter population we conclude that it originates from the plasma sheet or plasma sheet boundary layer. Panel C displays electron data as energy 


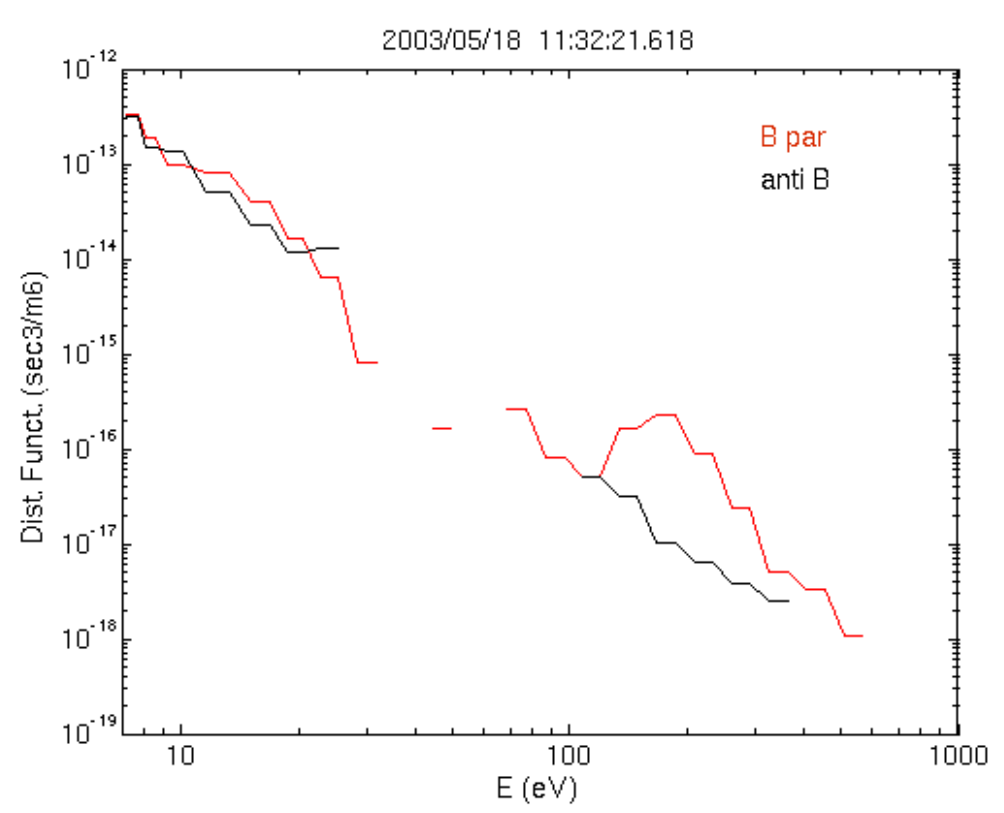

Fig. 13. 18 May 2003. Electron distribution function at 11:32:21.618 UT for upgoing electrons (black) and downgoing electrons (red) computed from PEACE data.

spectrograms, from top to bottom: downgoing, perpendicular and upgoing electrons.

During this polar cap crossing, HIA data reveal a succession of ion acceleration structures related to increases in the precipitating electron fluxes. On the other hand, during several crossings of the polar cap, strong fluxes of upgoing electrons were measured between the ion acceleration structures, particularly when the energy of the ion beams was large. Clear examples of such structures are provided in a companion paper by Teste et al. (2006) ${ }^{1}$. The polar cap thus reveals its filamentary nature during northward IMF conditions. However, during the 18 May 2003 event, we do not detect such large upward ionospheric electron fluxes (Fig. 11). This lack of measurable upward directed electrons can be due to the fact that they could have a very low energy and be mixed with the satellite photoelectron population whose energy range has been removed from Fig. 11. The electric current density calculated from FGM magnetic field data, using a single spacecraft under stationary hypothesis (not shown), is in agreement with particle data inside the broad ion structures, i.e. the current is upwardly directed. However, a detailed study of the current sheets associated with those events is beyond the scope of this paper.

Figure 12 displays additional information for the 18 May 2003 polar cap crossing illustrated in Fig. 11. The top panel of Fig. 12 shows the corresponding energy spectrogram for ions and the second panel for precipitating electrons. Panel C

\footnotetext{
${ }^{1}$ Teste, A., Fontaine, D., and Maggiolo, R.: CLUSTER observations of field-aligned currents above the polar cap by northward IMF, Ann. Geophys., submitted, 2006.
}

gives the energy at the maximum energy flux for both ions and electrons. Precipitating electrons with energy of the order of a few hundred eVs are simultaneously detected together with upflowing ions. The downward acceleration of electrons is evidenced by Fig. 13, which displays the electron distribution function at 11:32:21 UT for both downgoing and upgoing electrons during the crossing of the broadest acceleration structure. Low energy electrons are photoelectrons up to the energy step around $20 \mathrm{eV}$. At higher energies, the upgoing electron distribution function decreases with energy. On the contrary, the downgoing electron distribution function is strongly peaked around $200 \mathrm{eV}$. This clearly indicates that the electrons are downwardly accelerated.

The simultaneous observation of upflowing ion beams and downgoing accelerated electrons suggests that the main energy source for these ion beams is a parallel electric field. Electric field data (panel D) reveal the presence of converging electric field structures associated with these ion beams. Each of the structures is associated with sudden reversals in the local perpendicular electric field. These perpendicular electric fields reach values comprised between 2 and $6 \mathrm{mV} / \mathrm{m}$ whereas between the structures the perpendicular electric field is lower than $0.5 \mathrm{mV} / \mathrm{m}$. Such large converging electric fields probably do not map to the ionosphere but signals electrostatic shocks which are associated with parallel electric fields (see Mozer et al., 1977). The profile of the electric potential along the spacecraft trajectory has been calculated during the crossing of the structures using EDI electric field data (Fig. 12, panel D). The parallel potential was derived by integrating the observed electric field along the spacecraft trajectory. We assumed that the parallel potential was zero 
A)

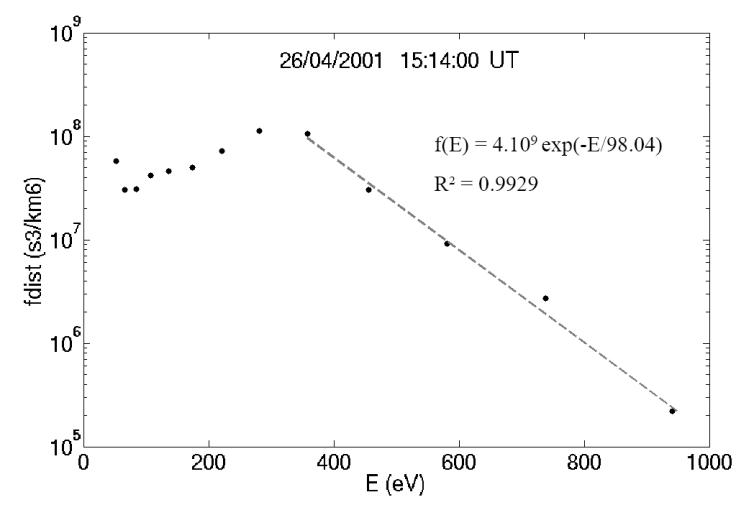

B)

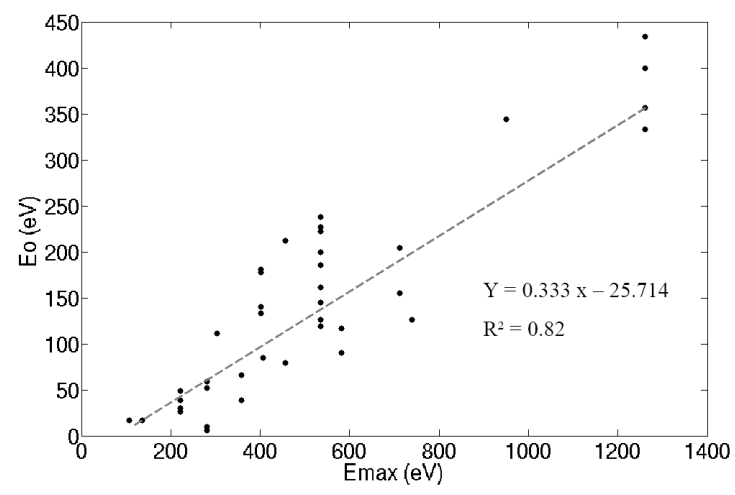

C)

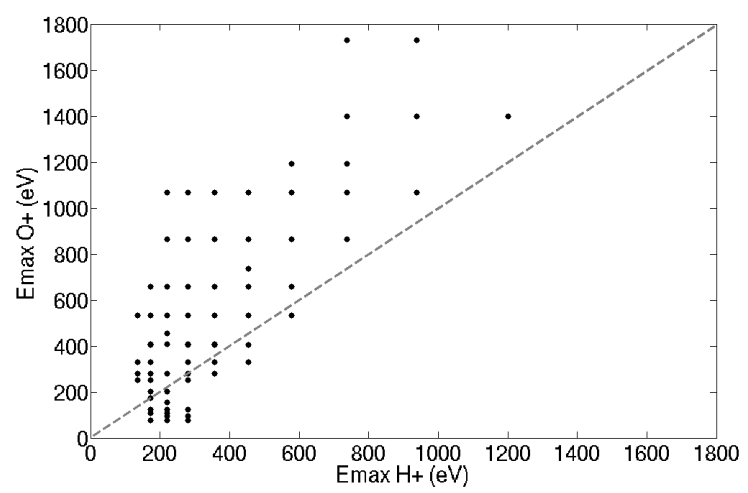

Fig. 14. 26 April 2001. From top to bottom: (A) Ion energetic distribution function at 15:14:00 UT. (B) Thermal energy versus peak energy. (D) $\mathrm{O}^{+}$ions energy versus $\mathrm{H}^{+}$ions energy.

on the edges of the ion beam. As it is shown in panel $\mathrm{E}$ of Fig. 12, the corresponding electric potential of about $1 \mathrm{kV}$ fits well the ion energy of the spectra maximum. This result is consistent with the assumption made above that the perpendicular potential observed at the spacecraft becomes a parallel potential below the spacecraft.

Such a current driven parallel electric field, related to the magnetic mirror force acting on the current carrying particles, is expected to appear when the particle flux inside the loss cone is insufficient to carry the field-aligned current (e.g. Knight, 1973; Boström, 2003, 2004). Note that the existence of the same kind of potential drop in the auroral zone is experimentally well established (e.g. Lyons et al., 1979; Akasofu, 1981; Ergun et al., 1998). Furthermore, previous study of polar cap arcs also showed that they are associated with a parallel potential drop of the order of a few $\mathrm{keV}$ (Zhu et al., 1997).

Using polar satellite data, Mozer et al. (2001) concluded that a parallel electric field greater than a few hundred volts extend upward to altitudes of 3.0 to 3.5 Earth radii in the auroral zone. Although not excluding the existence of a weak potential drop above this altitude, these authors suggested that 3.5 $R_{E}$ was the top of the acceleration region. In contrast, as we will show below, in the polar cap the parallel electric field extends at higher altitudes. At the Cluster orbit, at radial distances of about 6 Earth radii, the simultaneous observation of precipitating electrons and upflowing ions of similar energies (Fig. 12) indicates that the spacecraft is crossing the mid-altitude part of the acceleration region. In panel C of Fig. 12, representing precipitating electron and upflowing ion energies, we remark that the total acceleration energy $\left(E_{\max }\right.$ electrons $+E_{\max }$ ions) varies from about $200 \mathrm{eV}$ for the second structure to about $900 \mathrm{eV}$ for the third structure. For the two last structures, the electron energy is lower than that of the ions, while for the first two structures it is equal to the ion energy. If the electron and ion sources are cold, this clearly indicates that the parallel electric field altitude distribution varies from one structure to another. Our hypothesis about the temperature of the source is justified for ions because the source is the ionosphere. It is also true for electrons, as showed by PEACE measurements. Indeed, on the edges of the structure where ion energy is low, the electron energy falls off to less than $100 \mathrm{eV}$, which is lower than the energy of typical energetic polar rain electrons originating from the solar wind strahl (Fairfield and Scudder, 1985). These electron energies observed here are in better agreement with those of the halo solar wind electrons as the source of the polar cap precipitation (Winningham and Heikkila, 1974). We can thus infer that the accelerated electrons observed inside the structure gained a large part of their energy inside the structure, above the Cluster altitude. This indicates that a parallel electric field of the order of a few hundred $\mathrm{eV}$ can exist above 5 Earth radii along the polar cap field lines and that this represents a subsequent part of the total fieldaligned electric field.

In order to obtain more information on the ion acceleration and heating mechanisms, we performed a detailed study of the ion distribution functions and showed that the ions' parallel temperature increases as they are accelerated. We present here the results obtained during an event taken on 26 April 2001. Indeed, during this event, the Cluster spacecraft cross a broad acceleration structure corresponding to ion energies up to $1200 \mathrm{eV}$. Because of the slow variation in the ion energy at the borders of this structure the distribution functions are measured with a good accuracy. These upflowing ion distribution functions can be characterised by a sharp peak and a fall off at higher energies of the form of $\exp \left(-\mathrm{E} / \mathrm{E}_{0}\right)$ 


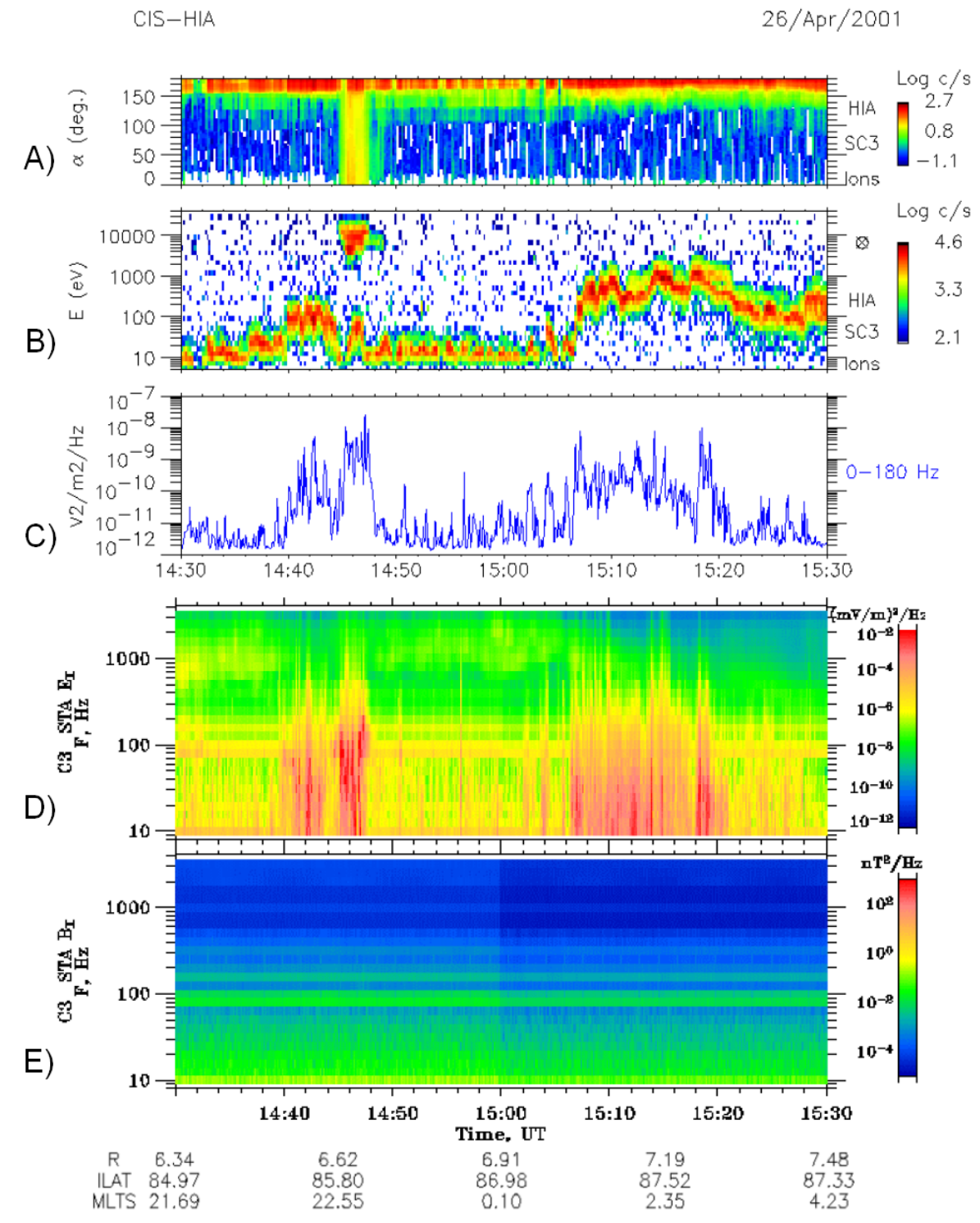

Fig. 15. 26 April 2001. From top to bottom: (A) Ion pitch-angle distribution from HIA for all ions. (B) Energy-time spectrogram from HIA for all ions. (C) Electric field spectral density from 0 to $180 \mathrm{~Hz}$ from the STAFF instrument. (D) Frequency-time spectrogram for electric field waves from STAFF in the frequency range from 10 to $3000 \mathrm{~Hz}$. (E) Frequency-time spectrogram for magnetic field waves from STAFF in the frequency range from 10 to $3000 \mathrm{~Hz}$.

(Fig. 14A). The parallel thermal energy $\mathrm{E}_{0}$ of the ions is correlated with their acceleration energy and is about $30 \%$ of the energy of the maximum of flux (Fig. 14B). Reiff (1988) made the same kind of study in the auroral zone and found similar results with thermal energies comprised between $20-30 \%$ of the peak energy. Outflowing ions thus reach thermal energies of the order of a few hundreds of $\mathrm{eV}$, much more than their ionospheric temperature of about $1 \mathrm{eV}$. Furthermore, $\mathrm{O}^{+}$ions are more energetic than $\mathrm{H}^{+}$ions, which is inconsistent with a quasi-static electric field as the only acting mechanism. This difference in energy is illustrated in Fig. 14, panel C, which represents the $\mathrm{O}^{+}$ions energy versus the $\mathrm{H}^{+}$energy for this specific event.

Those observations can be due to a two-stage process with preheating of ions perpendicularly to the magnetic field at low altitude followed by the acceleration by a parallel electric field, as proposed by Möbius et al. (1998). Due to the mirror force, this perpendicular energy will then be converted into parallel energy. Because more efficient wave heating of heavier ions in comparison with protons has been observed (e.g. Moore et al., 1986), it could explain the energy difference between oxygen ions and protons. For lower parallel 
electric fields this contribution would represent a larger fraction of the total energy and thus lead to a larger $\mathrm{E}_{\mathrm{O}^{+}} / \mathrm{E}_{\mathrm{H}^{+}}$ ratios. However, our observations show the opposite behaviour, with larger $\mathrm{E}_{\mathrm{O}^{+}} / \mathrm{E}_{\mathrm{H}^{+}}$ratios at high energies (Fig. 14, panel C). Furthermore, the thermal energy is correlated with the peak energy, indicating that the more the ions are accelerated, the more they are heated. It is thus more likely that ions are heated while they are accelerated, instead of being heated before entering the acceleration region. A possible mechanism explaining this heating and energy exchange is a two stream instability between $\mathrm{O}^{+}$and $\mathrm{H}^{+}$, due to the separation of these two populations in velocity space. This mechanism has been proposed to explain the same kind of observations in the auroral zone (Reiff et al., 1988; Lundin and Hultqvist, 1989).

In order to detect waves possibly associated with the energy transfer between $\mathrm{O}^{+}$and $\mathrm{H}^{+}$, we used wave data collected by the STAFF instrument during this event to identify wave activity coincident with acceleration and heating of the ions (Fig. 15). Data from both electric and magnetic waves in the frequency range below $3000 \mathrm{~Hz}$ are used. There is very little activity in the magnetic waves, indicating that the observed waves at frequencies below $\sim 500 \mathrm{~Hz}$ are electrostatic. Note that the electric field spectral density at low frequency is well correlated with the ion energy profile (panel C). Such broad-band electrostatic waves, covering the ion gyrofrequency of the major ion species, are commonly observed together with perpendicular heating via wave particle interaction, such as electrostatic ion cyclotron heating (see review by André and Yau, 1997). However, such mechanisms preferentially heat ions in the perpendicular direction. They cannot explain alone the ion distribution function we observe, which shows heating preferentially in the parallel direction. This observation of intense electrostatic waves associated with parallel heating is consistent with energy transfer from the faster $\mathrm{H}^{+}$to the slower $\mathrm{O}^{+}$via two-stream instabilities (e.g. Reiff et al., 1988; Krauklis et al., 2001). While we do not exclude the simultaneous occurrence of other wave particle interactions, these observations suggest that the twostream instability is a plausible mechanism for the required heating and energy exchange between oxygen ions and protons while they are accelerated by a parallel electric field. More work is needed, however, to substantiate this hypothesis.

\section{Conclusions}

Over the polar cap, the Cluster spacecraft observe $\mathrm{O}^{+}$and $\mathrm{H}^{+}$ion beams with energies up to a few $\mathrm{keV}$. They have been separated into two distinct categories: polar cusp ion beams originating from the vicinity of the polar cusp and "locally accelerated" ion beams. The former ones are associated with field-aligned $\mathrm{O}^{+}$and $\mathrm{H}^{+}$ions with differing energies $\left(\mathrm{E}_{\mathrm{O}^{+}}>\mathrm{E}_{\mathrm{H}^{+}}\right)$. The second ones are associated with $\mathrm{O}^{+}$and $\mathrm{H}^{+}$ions of similar energies.

During periods of negative or varying IMF $B_{z}$, ions originating from the cleft ion fountain are detected above the polar caps. The ions are heated/accelerated perpendicularly to the magnetic field at low altitude and then undergo an adiabatic convection drift above the polar cap. At Cluster altitudes, the ratio between the average energy of $\mathrm{O}^{+}$and $\mathrm{H}^{+}$ions is about 4 . This ratio is interpreted as due to a large spatial extension of the ionospheric source in the vicinity of the polar cusp, combined with the characteristic ion energy repartition inside the source for an antisunward convection: decreasing energy with increasing latitude. Sudden increases in the upflowing ion energy are detected along the Cluster trajectory. They are probably linked with pulses of the convection electric field, perhaps triggered by changes in the IMF. These ion acceleration structures have been shown to drift at a velocity comparable to the average convection speed.

Inside the polar cap, structures of accelerated ionospheric ions are observed mainly during prolonged periods of northward IMF. These structures are associated with downward accelerated electrons. In between the ion structures, upward electron beams with energies up to $50-100 \mathrm{eV}$ can be recorded (Teste et al., 2006) ${ }^{1}$. Particle and electric field measurement are consistent with ion acceleration by a quasistatic parallel electric field. The total potential drop of about $1 \mathrm{kV}$ is distributed along the magnetic field over distances larger than 5 Earth radii. During their acceleration ions are heated to thermal energy, reaching a few hundreds $\mathrm{eV}$ and energy is exchanged between ions of different masses, with heavy ions being more energetic than lighter ones. The involved mechanism could be an ion-ion two-stream instability between $\mathrm{H}^{+}$and $\mathrm{O}^{+}$ions. The properties of the polar rain electrons associated with these ion beams suggest that the ion outflows are associated with weak polar cap arcs.

Altogether these measurements indicate that the polar cusp is a source of energetic ionospheric plasma and as the cusp is observed for any orientation of the IMF, this source is continuous. The polar cap is on the contrary an intermittent source acting mainly when the IMF $B_{z}$ is northward directed. The associated acceleration mechanism and source region are different but lead to the observation of ions of similar energy at high altitude above the polar caps. More work is needed to assess the respective contribution of the cusp and of the polar cap in populating the magnetosphere with tens of $\mathrm{eV}$ to hundreds of eVs ions.

Acknowledgements. The authors are grateful to E. Penou for the development of the Cluster CIS software. E. Grigorenko thanks the support by RFBR grant Nr 04-02-17371, 03-02-16967, by grant HIII-17 39.2003.2, by INTAS Nr 03-51-3738 and YS Fellowship Nr 03-55-1880 and by Russian Science Support Foundation.

Topical Editor T. Pulkkinen thanks O. W. Lennartsson and another referee for their help in evaluating this paper. 


\section{References}

Akasofu, S.-I.: Auroral arcs and auroral potential structure, Physics of auroral arcs formation, Geophysical Monograph, 25, 1-4, 1981.

André, M. and Yau, A.W., Theories and observations of ion energization and outflow in the high latitude magnetosphere, Space Sci. Rev., 80, Issue 1/2, 27-48, 1997.

Balogh, A., Carr, C. M., Acuña, M. H., Dunlop, M. W., Beek, T. J., Brown, P., Fornaçon, K.-H., Georgescu, E., Glassmeier, K.H., Harris, J., Musmann, G., Oddy, T., and Schwingenschuh, K.: The Cluster Magnetic Field Investigation: overview of in-flight performance and initial results, Ann. Geophys., 19, 1207-1217, 2001.

Bogdanova, Y. V., Klecker, B., Paschmann, G., Kistler, L. M., Mouikis, C., Moebius, E., Rème, H., Bosqued, J.-M., Dandouras, I., Sauvaud, J.-A., Cornilleau-Wehrlin, N., Laakso, H., Korth, A., Bavassano-Cattaneo, M. B., Marcucci, M. F., Phan, T., Carlson, C., Parks, G., McFadden, J. P., McCarthy, M., and Lundin, R.: Investigation of the source region of ionospheric oxygen outflow in the cleft/cusp using multi-spacecraft observations by CIS onboard Cluster, Adv. Space R., 34, 11, 2459-2464, 2004.

Boström, R.: Kinetic and space charge control of current flow and voltage drops along magnetic field flux tubes: 1 . Kinetic effects, J. Geophys. Res., 108, A4, COA 5-1, 2003.

Boström, R.: Kinetic and space charge control of current flow and voltage drops along magnetic field flux tubes: 2 . Space charge effects, J. Geophys. Res., 109, A1, A01208, 2004.

Bouhram, M., Dubouloz, N., Jasperse, J. R., Pottelette, R., Senior, C., Delcourt, D., Carlson, C. W., Roth, I., Berthomier, M., and Sauvaud, J.-A.: Ion outflow and associated perpendicular heating in the cusp observed by Interball Auroral Probe and Fast Auroral Snapshot, J. Geophys. Res., 107, A2, SMP 4-1, 2002.

Bourham, M., Klecker, B., Paschmann, G., Rème, H., Blagau, A., Kistler, L., Puhl-Quinn, P., and Sauvaud, J.-A.: Multipoint analysis of the spatio-temporal coherence of dayside $\mathrm{O}^{+}$outflows with Cluster, Ann. Geophys., 22, 7, 2507-2514, 2004.

Cornilleau-Wehrlin, N., Chauveau, P., Louis, S., Meyer, A., Nappa, J. M., Perraut, S., Rezeau, L., Robert, P., Roux, A., de Villedary, C., de Conchy, Y., Friel, L., Harvey, C. C., Hubert, D., Lacombe, C., Manning, R., Wouters, F., Lefeuvre, F., Parrot, M., Pincon, J. L., Poirier, B., Kofman, W., and Louarn, P.: The CLUSTER Spatio-Temporal Analysis of Field Fluctuations (STAFF) Experiment, Space Sci. Rev., 79, 1-2, 107-136, 1997.

Cowley, S. W. H. and Lockwood M.: Excitation and decay of solar wind driven flows in the magnetosphere-ionosphere system, Ann. Geophys., 10, 103-115, 1992.

Delcourt, D. C., Giles, B. L., Chappell, C. R., and Moore, T. E.: Low-energy bouncing ions in the magnetosphere - A threedimensional numerical study of Dynamics Explorer 1 data, J. Geophys. Res., 93, 1859-1870, 1988.

Delcourt, D. C., Sauvaud, J.-A., Vaisberg, O. L., Avanov, L. A., Burch, J. L., and Waite Jr., J. H.: Signatures of impulsive convection in the magnetospheric lobes, Geophys. Res. Lett., 23, 129-132, 1996.

Dubouloz, N., Delcourt, D., Malingre, M., Berthelier, J.-J., and Chugunin, D.: Remote analysis of cleft ion acceleration using thermal plasma measurements from Interball Auroral Probe, Geophys. Res. Lett., 25, 2925-2928, 1998.
Dubouloz, N., Bourham, M., Senior, C., Delcourt, D., Malingre, M., and Sauvaud, J.-A.: Spatial structure of the cusp/cleft ion fountain: A case study using a magnetic conjugacy between Interball AP and a pair of Super-DARN radars, J. Geophys. Res., 106, A1, 261-274, 2001.

Ergun, R. E., Carlson, C. W., McFadden, J. P., Mozer, F. S., Delory, G. T., Peria, W., Chaston, C. C., Temerin, M., Elphic, R., Strangeway, R., Pfaff, R., Cattell, C. A., Klumpar, D., Shelley, E., Peterson, W., Moebius, E., and Kistler, L.: FAST satellite observations of electric field structures in the auroral zone, Geophys. Res. Lett., 25, 2025-2028, 1998.

Escoubet, C. P., Fehringer, M., and Goldstein, M.: The Cluster mission, Ann. Geophys., 19, 1197-1200, 2001.

Fairfield, D. H. and Scudder, J. D.: Polar rain electrons - Solar coronal electrons in the earth's magnetosphere, J. Geophys. Res., 90, A5, 4055-4068, 1985.

Jacobsen, B., Sandholt, P. E., Burke, W. J., Denig, W. F. and Maynard, N. C.: Optical signatures of prenoon auroral precipitation: Sources and responses to solar wind variations. J. Geophys. Res., 100, 8003-8012, 1995.

Jayachandran, P. T. and MacDougall, J. W.: Central polar cap convection response to short duration southward Interplanetary Magnetic Field, Ann. Geophys., 18, 887-896, 2000.

Johnstone, A. D., Alsop, C., Burdge, S., Carter, P. J., Coates, A. J., Coker, A. J., Fazakerley, A. N., Grande, M., Gowen, R. A., Gurgiolo, C., Hancock, B. K., Narheim, B., Preece, A., Sheather, P. H., Winningham, J. D., and Woodliffe, R. D.: PEACE: a Plasma Electron and Current Experiment, Space Sci. Rev., 79, 351-398, 1997.

Knight, S.: Parallel electric Fields., Planet. Space Sci., 21, 741-750, 1973.

Korth, A., Fränz, M., Zong, Q.-G., Fritz, T. A., Sauvaud, J.-A., Rème, H., Dandouras, I., Friedel, R., Mouikis, C. G., Kistler, L. M., Möbius, E., Marcucci, M. F., Wilber, M., Parks, G., Keiling, A., Lundin, R., and Daly, P. W.: Ion injections at auroral latitude during the March 31, 2001 magnetic storm observed by Cluster, Geophys. Res. Lett., 31(20), 1-4, 2004.

Krauklis, I., Johnstone, A. D., and Peterson, W. K.: Acceleration of ionospheric $\mathrm{O}^{+}$ions on open field lines in the Low-Latitude Boundary Layer and the cusp region, J. Geophys. Res., 106, A12, 29611-29618, 2001.

Lockwood, M., Waite Jr., J. H., Moore, T. ., Johnson, J. F. E., and Chappell, C. R.: A new source of Suprathermal $\mathrm{O}^{+}$ions near the dayside polar cap boundary, J. Geophys. Res., 90, 4099-4116, 1985.

Lockwood, M. and Cowley, S. W. H.: Comment on "A statistical study of the ionospheric convection response to changing interplanetary magnetic field conditions using the assimilative mapping of ionospheric electrodynamics technique" by Ridley et al., J. Geophys. Res., 104, 4387-4391, 1999.

Lundin, R. and Hultqvist, B.: Ionospheric plasma escape by highaltitude electric fields: Magnetic moment "pumping", J. Geophys. Res., 94, A6, 6665-6680, 1989.

Lyons, L. R., Evans D. S., and Lundin, R.: An observed relation between magnetic field aligned electric fields and downward electron energy flux in the vicinity of auroral forms, J. Geophys. Res., 84, 457-461, 1979.

Möbius, E., Tang, L., Kistler, L. M., Popecki, M., Lund, E. J., Klumpar, D., Peterson, W., Shelley, E. G., Klecker, B., Hov- 
estadt, D., Carlson, C. W., Ergun, R., McFadden, J. P., Mozer, F., Temerin, M., Cattell, C., Elphic, R., Strangeway, R., Pfaff, R.: Species dependent energies in upward directed ion beams over auroral arcs as observed with FAST TEAMS, Geophys. Res. Lett., 25, 2029-2032, 1998.

Moore, T. E., Lockwood, M., Chandler, M. O., Waite Jr., J. H., Chappell, C. R., Persoon, A., and Sugiura, M.: Upwelling $\mathrm{O}^{+}$ ion source characteristics, J. Geophys. Res., 91, 7019-7031, 1986.

Moore, T. E., Lundin, R., Alcayde, D., André, M., Ganguli, S. B., Temerin, M., and Yau, A.: Source processes in the high-altitude ionosphere, Space Sci. Rev., 88, 1-2, 7-84, 1999.

Mozer, F. S., Carlson, C. W., Hudson, M. K., Torbert, R. B., Parady, B., Yatteau, J., and Kelley, M. C.: Observation of paired electrostatic shocks in the polar magnetosphere, Phys. Rev. Lett., 38, 292-295, 1977.

Mozer, F. S. and Hull, A.: Origin and geometry of upward parallel electric fields in the auroral acceleration region, J. Geophys. Res., 106, A4, 5763-5778, 2001.

Nilsson, H., Joko, S., Lundin, R., Rème, H., Sauvaud, J.-A., Dandouras, I., Balogh, A., Carr, C., Kistler, L., Klecker, B., Carlson, C., Bavassano-Cattaneo, M., and Korth, A.: The structure of high altitude $\mathrm{O}^{+}$energization and outflow: a case study, Ann. Geophys., 22, 7, 2497-2506, 2004.

Paschmann, G., Quinn, J. M., Torbert, R. B., Vaith, H., McIlwain, C. E., Haerendel, G., Bauer, O. H., Bauer, T., Baumjohann, W., Fillius, W., Förster, M., Frey, S., Georgescu, E., Kerr, S. S., Kletzing, C. A., Matsui, H., Puhl-Quinn, P., and Whipple, E. C.: The Electron Drift Instrument on Cluster: overview of first results, Ann. Geophys., 19, 10, 1273-1288, 2001.

Peterson, W. K. and Shelley, E. G.: Origin of the plasma in a crosspolar cap auroral feature (theta aurora), J. Geophys. Res., 89, 6729-6736, 1984.

Reiff, P. H., Collin, H. L., Craven, J. D., Burch, J. L., Winningham, J. D., Shelley, E. G., Frank, L. ., and Friedman, M. .: Determination of auroral electrostatic potential using high- and lowaltitude particle distributions, J. Geophys. Res., 93, A7, 74417465, 1988.

Rème, H., Aoustin, C., Bosqued, J.-A., et al.: First multispacecraft ion measurements in and near the earth's magnetosphere with the identical Cluster Ion Spectrometry (CIS) Experiment, Ann. Geophys., 19, 1303-1354, 2001.
Ridley, A. J., Lu, G., Clauer, C. R., and Papitashvili, V. O.: Reply, J. Geophys Res, 104, 4393-4396, 1999.

Sauvaud, J.-A. and Delcourt, D.: A numerical study of suprathermal ionospheric ion trajectories in three-dimensional electric and magnetic field models, J. Geophys. Res., 92, 5873-5884, 1987.

Sauvaud, J.-A., Popescu, D., Delcourt, D. C., Parks, G. K., Brittnacher, M., Sergeev, V., Kovrazhkin, R. A., Mukai, T., and Kokubun, S.: Sporadic plasma sheet ion injections into the highaltitude auroral bulge: Satellite observations, J. Geophys. Res., 104, A12, 28 565-28 586, 1999.

Shelley, E. G., Johnson, R. G., and Sharp, R. D.: Satellite observations of energetic heavy ions during a geomagnetic storm, J. Geophys. Res., 77, 6104-6110, 1972.

Shelley, E. G., Peterson, W. K., Ghielmetti, A. G., and Geiss, J.: The polar ionosphere as a source of energetic magnetospheric plasma, Geophys. Res. Lett., 9, 941-945, 1982.

Sibeck, D. G., Lopez, R. E., and Roelof, E. C.: Solar wind control of the magnetopause shape, location, and motion, J. Geophys. Res., 96, 5489-5495, 1991.

Thelin, B., Aparicio, B., and Lundin, R.: Observations of upflowing ionospheric ions in the mid-altitude cusp/cleft region with the Viking satellite, J. Geophys. Res., 95, 5931-5939, 1990.

Tsyganenko, N. A.: A magnetospheric magnetic field model with a warped tail current sheet, Planet. Space Sci. 37, 5-20, 1989.

Valek, P. W., Perez, J. D., Jahn, J.-M., Pollock, C. J., Wüest, M. P., Friedel, R. H. W., Moore, T. E., Peterson, W. K.: Outflow from the ionosphere in the vicinity of the cusp, J. Geophys. Res., 107, A8, SMP 13-1, 2002.

Volland, H.: A model of the magnetospheric electric convection field, J. Geophys. Res., 83, 2695-2699, 1978.

Winnigham, J. D. and Heikkila, W. J.: Polar cap auroral electron fluxes observed with ISIS 1, J. Geophys. Res., 79, 949-957, 1974.

Yau, A. W. and André, M.: Sources of ion outflow, Space Science Review, 80, 1-2, 1-25, 1997.

Zhu, L., Schunk, R. W., and Sojka, J. J.: Polar cap arcs: a review, J. Atmos. Terrest. Phys., 59, 1087-1126, 1997. 